\title{
Bases para una edición crítica del Libro de la caza de las aves de Pero López de Ayala
}

\author{
Foundations for a critical edition of \\ Pero López de Ayala's Libro de la caza de las aves
}

\author{
Déborah Dietrick Smithbauer \\ José Manuel Fradejas Rueda \\ Universidad de Valladolid
}

RESUMEN: La primera edición de Libro de la caza de las aves (1869) fue encomendada a Lafuente Alcántara pero fue finalizada, con dificultades, por Gayangos. Más de un siglo después aparecen las primeras ediciones críticas. Aunque los estudios de Cummins (1986) y Montoto Delgado (1999) son de indudable valía, se han detectado errores tanto en su metodología como en la interpretación de los datos. Esto, unido a la aparición de nuevos manuscritos, aconseja la publicación de una nueva edición crítica, que se hará en formato digital siguiendo el sistema TEI (Text Encoding Initiative).

Palabras clave: Pero López de Ayala, Libro de la caza de las aves, edición crítica, cetrería, Edad Media, TEI.

ABSTRACT: The Libro de la caza de las aves' first edition (1869) was entrusted to Lafuente Alcántara but it was Gayangos who finally published the text. More than a hundred years would pass before the first critical editions appeared. Although Cummins' (1986) and Montoto Delgado's (1999) studies undoubtably offer valuable information, errors have been detected both in their methodology and in the interpretation of their data. In addition to this, the fact that new manuscripts have been discovered paves the way for a new critical edition, which will be published in a digital format using TEI (Text Encoding Initiative).

Keywords: Pero López de Ayala, Libro de la caza de las aves, critical edition, falconry, Middle Ages, TEI.

* Este trabajo forma parte del proyecto de investigación FFI2010-15128 del Ministerio de Ciencia e Inovación y, parcialmente, VA046A09 de la Junta de Castilla y León. 
Entre 1385 y 1386 , durante los quince meses que estuvo preso en el castillo de Óbidos, tras la batalla de Aljubarrota (14 de agosto de 1385), el canciller Pero López de Ayala (1332-1407) compuso el más famoso y difundido libro español de cetrería de todos los tiempos. Lo escribió porque «en esta arte e çiençia dela caça delas aves oy e vi muchas dubdas [...] e por esto acorde de trabajar por non estar oçioso de poner en este pequeño libro todo aquello que mas çierto falle» ${ }^{1}$. Ese «pequeño libro» no es otro que el Libro de la caça de las aves.

El Libro de la caça de las aves está constituido por tres partes fundamentales. La primera, que comprende los capítulos I-VII y XLI-XLV, habla con todo detalle de las diversas aves de rapiña; comienza por describir y diferenciar las auténticas aves de rapiña de las que no lo son, para continuar con la descripción de las especies utilizadas en la caza y su distribución geográfica.

La segunda sección, dedicada a la enseñanza y entrenamiento de las aves de caza, ocupa un único capítulo, el VIII, que, además de ser el más extenso de todos, está totalmente cuajado de anécdotas de otros tiempos mejores. La tercera es la médico-farmacéutica (IX-XL y XLVI). En ella sigue un esquema lógico: primero describe y explica las causas de la enfermedad o herida — «Acaesce algunas vegadas»—; después expone los síntomas — «e conosçerloas en esto»—; para en último lugar ofrecer los remedios — «E esta dolencia se cura assy»—. Debido a posibles complicaciones — «Otro sy deues saber que desta agua faze otra peor»-, se pueden encadenar uno tras otro. Esporádicamente incluye recomendaciones para mantener más sanas las aves de caza.

Al final hay tres capítulos que suponen una auténtica novedad y que se harán tópicos en la producción cetrera posterior. Uno lo dedica a lo que llama «el passo de las aves» (cap. XLV), es decir, a los movimientos migratorios y a qué se deben, con lo que quizá nos encontremos ante el primer estudio ornitológico en español. En el capítulo XLVII expone el «feramental del mjsteryo», que no solo incluye caperuzas, lonjas, pihuelas, gañivetes, luvas, etc., sino también las drogas y simples necesarios para tratar y curar las aves de caza. Estos últimos capítulos no son totalmente originales pues el Canciller traduce, adapta y amplía el Livro de falcoaria de Pero Menino, «falconero ... del Rey don Ferando de Portugal».

Este libro que acabamos de describir ha gozado de una amplísima difusión manuscrita $^{2}$ y ha sido fuente de varias obras ${ }^{3}$, incluida una sátira ${ }^{4}$ A pesar de

1 Pero López de Ayala, Libro de la caza de las aves. El MS 16.392 (British Library, Londres), ed. John Cummins, London, Tamesis Books, 1986, pág. 50.

${ }^{2}$ En la actualidad se conocen treinta y cinco copias realizadas entre principios del siglo XV y el XVIII. En el apéndice final se encuentra la relación de los testimonios censados del Libro de la caza de las aves de Pero López de Ayala. Cada uno de ellos se identifica con una sigla. La base 
ello, no conoció las prensas hasta el último tercio del siglo XIX, cuando la Sociedad de Bibliófilos Españoles publicó la primera edición, aunque con un título ligeramente diferente: Libro de las aves de caza. Desde entonces han aparecido seis ediciones con distintas filosofías editoriales y diferente interés y éxito ${ }^{5}$.

se encuentra en la edición de John Cummins (Pero López de Ayala, Libro de la caza de las aves, cit., págs. 23-32); la continuó Germán Orduna («Libro de la caça de las aves», en Carlos Alvar y José Manuel Lucía Megías, coord., Diccionario filológico de literatura medieval española: Textos y transmisión, Madrid, Castalia, 2002, págs. 895-899); y la ha completado y corregido José M. Fradejas Rueda ( $«$ De nuevo sobre los manuscritos del Libro de la caça de las aves de Pero López de Ayala», en Lengua Viva. Homenaje a César Hernández, Alonso, Valladolid, Universidad y Diputación Provincial, págs. 1099-1115). En esa misma tabla se incluyen, entre paréntesis, las siglas que utilizó Manuel Delgado Montoto (Edición crítica del Libro de la caza de las aves, de Pero López de Ayala, tesis de doctorado, Madrid, UNED, 1998). No se tienen en cuenta las establecidas por Madeleine Montandon-Hummel («Libro de cetrería: edición basada en los códices del siglo XV», tesis de doctorado, Basilea, Discount Print, 1986).

${ }^{3}$ Obras deudoras de la de Ayala son el Libro de cetrería de Juan de Sahagún (siglo XV; se conocen cuatro copias, todas ellas recogidas en códices que también tienen una copia de la obra de Ayala), el Libro de acetrería y montería de Juan Vallés (1556; se conservan once copias), el Libro de cetrería de Luis de Zapata (1583; existen tres copias) y el Arte da caça de altaneria de Diogo Fernandes Ferreira (1616; impreso y una traducción manuscrita al castellano). La mencionan, sin tener una clara deuda, el Discurso del halcón esmerejón del Conde de Puñonrostro (Madrid, Biblioteca Real, ms. II-1318) y el Libro de cetrería de caza de azor de Fadrique de Zúñiga y Sotomayor (1565; impreso [Salamanca, Juan de Cánova, 1565] y un manuscrito de autor Madrid, BNE, ms. 19196).

${ }^{4}$ El Libro de cetrería de Evangelista, escrito en la época de Enrique IV de Castilla (14251474, rey 1454). Es un breve escrito en el que se burla de las aves de cetrería, de los cazadores y de los desvelos de estos para mantenerlas. Antonio Paz y Meliá ( «Libro de cetrería de Evangelista y una profecía del mismo, con prólogo, variantes, notas y glosario», Zeitschrift für Romanische Philologie, 1, 1877, págs. 222-246) vio en este tratadito una crítica a la obra de Sahagún, pero una lectura atenta demuestra que, si bien hay muchos puntos de contacto entre ambas obras, hay otros en los que se ve claramente que su modelo es el libro del canciller Ayala, ya que algunos de sus chistes están construidos sobre pasajes no utilizados por Sahagún, pero sí por Ayala (Fradejas Rueda, Evangelista's «Libro de cetrería»: A fifteenth-century satire of falconry books, London, King's College London Centre for Late Antique and Medieval Studies, 1992, págs. xxxi-xxxii). Se conocen nueve copias.

${ }^{5}$ Las ediciones publicadas, en orden cronológico, son las de Emilio Lafuente Alcántara y Pascual de Gayangos (El Libro de las aves de caça del canciller López de Ayala con las glosas del Duque de Alburquerque, Madrid, Bibliófilos Españoles, 1869); la de José Gutiérrez de la Vega («Libro de la caza de las aves, et de sus plumages, et dolencias, et melecinamientos. Del canciller Pedro López de Ayala», en Libros de cetrería de el príncipe y el canciller, Madrid, M. Tello, 1879, págs. 136-344); José Fradejas Lebrero (Pero López de Ayala, Libro de la caza de las aves, Madrid, Castalia, $1^{\mathrm{a}}$ ed., 1959, $2^{\mathrm{a}}$ ed., 1969); la de Madeleine Montandon-Hummel («Libro de cetrería: edición basada en los códices del siglo XV», cit.); la de John Cummins (Pero López de Ayala, Libro de la caza de las aves, cit.); la de José Manuel Fradejas Rueda (Texto y concordancias del MS Additional 16392 de la British Library: «Libro de la caça de las aues» de Pero López de Ayala, Madison, Hispanic Seminary of Medieval Studies, 1992, una transcripción según la normas del HSMS del manuscrito de la British Library); y la de Manuel Delgado Montoto (Edición crítica del Libro de la caza de las aves, cit.). 
A pesar de que algunas han sido objeto de reseñas y comentarios detenidos ${ }^{6}$, creemos necesario examinarlas con cierta demora.

Emilio Lafuente Alcántara y Pascual de Gayangos. La edición de la Sociedad de Bibliófilos Españoles (SBE) tuvo un azaroso proceso editorial que la ha lastrado y ha hecho que se la menosprecie. Cuando ya estaban impresos los doce primeros pliegos de la edición le sobrevino la muerte a Emilio Lafuente Alcántara, erudito al que la SBE había encargado el trabajo. Lo retomó años después Pascual de Gayangos, que se queja (1869: vi-vii) del lamentable estado en que encontró los papeles de Lafuente Alcántara cuando se hizo cargo del proyecto. Tal era el desbarajuste que no se sabe a ciencia cierta qué manuscritos pudo utilizar para su edición. El examen tanto del prólogo como de las notas a pie de página muestra que hizo uso de ocho testimonios, que se designan con las letras A, B, C, D, E, F, G y $\mathrm{H}^{7}$.

Gayangos explica que $\mathrm{A}_{\mathrm{LA}}$, el testimonio más antiguo de los que se conocían, propiedad del conde de Altamira, era un manuscrito «en folio menor y en pergamino avitelado, y de letra, al parecer, del siglo XV» (1869: xvi-xvii). Este manuscrito ha desaparecido sin dejar rastro. De los treinta y cinco manuscritos que conocemos en la actualidad, el único escrito sobre pergamino es el ms. B2583 de la Hispanic Society of America (U), pero no es el testimonio de base por dos motivos. Primero, en la época en que se publicó la edición de Bibliófilos Españoles era propiedad del conde de Ezpeleta. Segundo, ninguno de los rasgos que podría caracterizarlo concuerda con los del manuscrito del conde de Altamira.

No hay ninguna indicación con respecto a los tres testimonios marcados

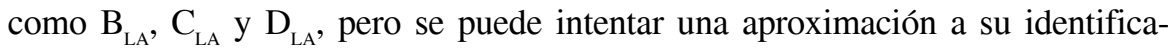

\footnotetext{
${ }^{6}$ La edición de Gutiérrez de la Vega (1879) la reseñaron Joaquín Badía Andreu, La Ilustración Venatoria, 8, 1885, págs. 67-68; Enrique de Leguina, La Ilustración Venatoria, 8, 1885, pág. 43; y Manuel Revilla, La Ilustración Venatoria, 8, 1885, pág. 27. La edición de Montandon-Hummel la revisaron Albert Gier, Revue de Linguistique Romane, 51, 1987, págs. 596-597 y Juan Carlos Conde, Dicenda: Cuadernos de Filología Hispánica, 10, 1991-1992, págs. 349-354. La edición de Cummins fue reseñada por Marcella Ciceri, Romanische Forschungen, 100, 1988, págs. 469-471; Ivy A. Corfis, Hispanic Review, 58, 1990, págs. 110-112; José Fradejas Lebrero, Ínsula, núm. 493, dic. 1987, págs. 5-6; José Manuel Fradejas Rueda, Epos, 4, 1988, 481-486; Michel Garcia, Bulletin of Hispanic Studies, 77, 1990, 183; Albert Gier, Zeitschrift für Romanische Philologie, 104, 1988, págs. 394-396; Fernando Gómez Redondo, Vox Romanica, 47, 1988, págs. 298-302; David Hook, Journal of Hispanic Philology, 14, 1989-1990, págs. 178-181; y Baudouin Van den Abeele, Scriptorium, 44:1, 1990 = Bulletin Codicologique, 1, n 195, pág. *60.

${ }^{7}$ En este trabajo nos vemos obligados a manejar tres series de siglas. Con el fin de diferenciar las series alfabéticas, marcamos las siglas utilizadas por Lafuente Alcántara con el subíndi$\mathrm{ce}_{\mathrm{LA}}$, de modo que estos siete testimonios aparecerán a lo largo de este estudio como $\mathrm{A}_{\mathrm{LA}}, \mathrm{B}_{\mathrm{LA}}$ $\mathrm{C}_{\mathrm{LA}}, \mathrm{D}_{\mathrm{LA}}, \mathrm{E}_{\mathrm{LA}}, \mathrm{F}_{\mathrm{LA}}, \mathrm{G}_{\mathrm{LA}} \mathrm{y}_{\mathrm{LA}}$.
} 
ción por medio del examen de las pocas variantes que se ofrecen en las notas a pie de página.

Los manuscritos $\mathrm{B}_{\mathrm{LA}}$ y $\mathrm{D}_{\mathrm{LA}}$ de Lafuente Alcántara comparten la misma variante en muchos $\operatorname{casos}^{8}$; en otras ocasiones cada manuscrito tiene una lectura diferente ${ }^{9}$; pero también hay lecciones exclusivas ya de $\mathrm{B}_{\mathrm{LA}}{ }^{10}$ ya de $\mathrm{D}_{\mathrm{LA}}{ }^{11}$. Tras analizarlas hemos llegado a la conclusión de que los testimonios $\mathrm{B}_{\mathrm{LA}}$ y $\mathrm{D}_{\mathrm{LA}}$ se corresponden con los manuscritos 1464 (B en la clasificación actual) y 4208 (G en la clasificación actual) de la Biblioteca Nacional de España respectivamente.

En un principio hubo un segundo candidato para el testimonio $\mathrm{B}_{\mathrm{LA}}$ : el ms. II-1366 de la Biblioteca de Palacio (O en nuestra clasificación). Tanto BNE 1464 como BPR II-1366 presentan una serie de variantes comunes que hacen difícil establecer cuál de ellos podría ser $\mathrm{B}_{\mathrm{LA}}$. En el capítulo XLVI «De cómo se deuen enxerir las péñolas quebradas» ${ }^{12}$ se informa de que «el MS. B. hace de este párrafo capítulo aparte» ${ }^{13}$. Esta es una peculiaridad que comparten BNE 1464 y BPR II-1366.

Muchas otras de las variantes que se ofrecen como propias de $\mathrm{B}_{\mathrm{LA}}$-que en la tabla todos los capítulos, tras el ordinal, lean «que fabla de...»; que en esta misma tabla falte la rúbrica «De la caida, o de la abatidura del falcón en que él fiere» ${ }^{14}$; o que en el capítulo sexto se omita la frase «et en francia son llamados laneros de crao» ${ }^{15}$ - S Sin embargo, la posibilidad de que $O$ pudiera haber sido el manuscrito $\mathrm{B}_{\mathrm{LA}}$ se desvanece ante el hecho de que $\mathrm{O}$ lee correctamente donde Lafuente anota variantes erróneas para $\mathrm{B}_{\mathrm{LA}}$. Así, en la frase «et prueua si querrá sobir en la mano á toda ${ }^{16}$ la lonja á la lua larga» ${ }^{17}$ las dos últimas palabras se han convertido en «lita larza» en B (fol. 35v) mientras que $\mathrm{O}$ presenta la lección correcta «a la luua larga» (fol. 19v). En este mismo capítulo octavo, en cierto momento se prescribe: «et ponle sienpre la lúa de yuso de los pies» ${ }^{18}$,

${ }^{8}$ Lafuente Alcántara, ed. cit. págs. 5, n. 3-4; 6, n. 1-2; 7, n. 1, 3-5 y 7; 8, n. 2-3, 5; 32, n. 3; 36 , n. $1 ; 42$, n. $1 ; 44$, n. $1 ; 46$, n. $1 ; 50$, n. 3, 65, n. 1 .

${ }^{9}$ Ibíd., págs. 50 , n. 4 , 98 , n. 1,122 , n. 1,123 , n. 1,125 , n. 1,139 , n. 2 ; 147, n. 2; 149, n. 1 ; 154, n. 1 .

${ }^{10}$ Ibíd., págs. 2 , n. $1-4 ; 3$, n. $1-2 ; 4$, n. $1 ; 5$, n. $1 ; 6$, n. $3 ; 7$, n. 2 y 8; 56, n. $1 ; 73$, n. $1 ; 122$, n. $2 ; 139$, n. $1 ; 160$, n. 1 .

${ }^{11}$ Ibíd., págs. 4, n. 2-3; 8, n. 1; 10, n. 1-2; 111, n. 1; 147, n. 1; 155, n. 1.

12 Ibíd., págs. 157-162.

13 Ibíd., pág. 160 nota.

14 Ibíd., pág. 8 y que se localiza en los manuscritos BNE 1464 (B), fol. 7r y BPR II-1366 (O), fol. $4 \mathrm{v}$.

${ }^{15}$ Ibíd., pág. 32 y que se localiza en los manuscritos BNE 1464 (B), fol. 27v y BPR II-1366 (O), fol. 15r.

${ }^{16}$ El sintagma á toda es una pésima transcripción de atada.

17 Ibíd., págs. 41-42.

18 Ibíd., pág. 46. 
pero en B (BNE 1464, fol. 40r) «la lúa» se transforma en «el gusano», lo que no sucede en O, que lee «la luua» (fol. 22r). Por consiguiente, la única posible identificación para el testimonio $\mathrm{B}_{\mathrm{LA}}$ es el ms. 1464 de la BNE (B de nuestra clasificación).

$\mathrm{El}$ hecho de que la mayoría de las variantes atribuidas a $\mathrm{D}_{\mathrm{LA}}$ aparezcan también en $\mathrm{B}_{\mathrm{LA}}$ nos ha permitido establecer que $\mathrm{D}_{\mathrm{LA}}$ debe identificarse con el ms. 4208 de la $\mathrm{BNE}$ ( $\mathrm{G}$ de nuestra clasificación). Las pruebas son las mismas que nos han permitido desechar que $B_{\mathrm{LA}}$ pudiera haber sido el ms. II-1366 de la Biblioteca de Palacio: el que en la frase «et prueua si querrá sobir en la mano á toda la lonja á la lua larga ${ }^{19}$ las dos últimas palabras se hayan convertido en «lita larza» ${ }^{20}$ y que «la lúa» en «et ponle sienpre la lúa de yuso de los pies» ${ }^{21}$ se haya transformado en «el gusano» ${ }^{22}$ demuestra sin duda alguna que el $\mathrm{D}_{\mathrm{LA}}$ es el ms. 4208 de la BNE.

Más complicado es tratar de identificar los mss. $\mathrm{C}_{\mathrm{LA}}, \mathrm{E}_{\mathrm{LA}}, \mathrm{F}_{\mathrm{LA}}, \mathrm{G}_{\mathrm{LA}}$ y $\mathrm{H}_{\mathrm{LA}}$ debido a las poquísimas variantes que ofrece la edición de Lafuente Alcántara. En verdad, con estos cuatro testimonios nos moveremos más dentro de la conjetura que de la prueba fehaciente e incontestable.

$\mathrm{F}_{\mathrm{LA}}, \mathrm{G}_{\mathrm{LA}}$ y $\mathrm{H}_{\mathrm{LA}}$ se citan una única vez cada uno. Las variantes aportadas por $\mathrm{F}_{\mathrm{LA}}$ y $\mathrm{G}_{\mathrm{LA}}$ son inútiles ${ }^{23}$ : la lectura editada dice mil sande mientras que $\mathrm{F}_{\mathrm{LA}}$ lee miel sana y $\mathrm{G}_{\mathrm{LA}}$ miel saña, que es la lectura arquetípica. La lección que Lafuente Alcántara recoge en $\mathrm{H}_{\mathrm{LA}}$ también es inservible para nuestro objetivo puesto que ninguna de las lecciones recopiladas por Delgado Montoto - flachas (lectura crítica), plachas, flarichas, franchas y flanchos ${ }^{24}$ — ni por Cummins — flanchas (lectura crítica), plachas, franchas, flachas, planchas, flauchans ${ }^{25}$ — se asemeja a la recogida por Lafuente en su testimonio $\mathrm{H}_{\mathrm{LA}}$, el cual lee flamachas.

$\mathrm{C}_{\mathrm{LA}}$ aporta seis variantes:

1. Niebla por Mena ${ }^{26}$

2. no estar en esto ocioso en vez de por no estar oçioso ${ }^{27}$

3. tage por tagre ${ }^{28}$

${ }^{19}$ Ibíd., págs. 41-42.

${ }^{20}$ BNE, mss. 1464 , fol. $35 \mathrm{v}$ y 4208 , fol. $19 \mathrm{v}$.

${ }^{21}$ Lafuente Alcántara, ed. cit., pág. 46.

22 BNE, mss. 1464, fol. 40r; 4208, fol. 22r.

${ }^{23}$ Lafuente Alcántara, ed. cit., pág. 95, n. 2.

${ }^{24}$ Manuel Delgado Montoto, Edición crítica del «Libro de la caza de las aves», de Pero López de Ayala, Madrid, Ediciones Calasancias, 2007, pág. 172, n. 224. De esta edición existen varias, valga la redundancia, ediciones (véase la explicación más adelante); empleamos la más moderna ya que es la única completa.

${ }^{25}$ Cummins, ed. cit., pág. 89, n. 141.

${ }^{26}$ Lafuente Alcántara, ed. cit., pág. 1, n. 1.

${ }^{27}$ Ibíd., pág. 3, n. 3.

${ }^{28}$ Ibíd., pág. 32, n. 1. 


\section{4. guante por lúa larga ${ }^{29}$}

5. el guante por la lúa ${ }^{30} \mathrm{y}$

6. encorado en lugar de curado $^{31}$

Vayamos por partes. El obispo don Gonzalo, al que el Canciller dedicó su obra, solo aparece bajo la forma Niebla en el ms. 4260 de la BNE.

La lectura no estar en esto ocioso no se ha documentado en ninguno de los testimonios de la BNE, aunque parece ser la que presenta $\mathrm{H}^{32}$.

Este manuscrito $\mathrm{H}$ parece decir algo parecido a tage (fol. 11v), aunque Cummins anota sage y se pregunta si podría ser fage $e^{33}$ (que es lo que nosotros leemos).

El primer caso de la lección el guante se documenta en $\mathrm{H}$ (fol. 16r); sin embargo, la segunda instancia, que en el ms. H se localiza en el fol. 18v, dice la aluda. El único testimonio que dice el guante en este punto es Cc (fol. 26r), manuscrito que nunca ha estado en Madrid.

El último caso es inútil ya que encorado es la lectura que presentan todos los manuscritos salvo $\mathrm{BK}$, que leen curado (la lectura atribuida a $\mathrm{A}_{\mathrm{LA}}$ por Lafuente); LW, que presentan encuirado; y DDd, que dicen soldado.

Por tanto, no se puede establecer cuál fue el manuscrito que Lafuente Alcántara marca como $\mathrm{C}_{\mathrm{LA}}$, aunque es posible que pudiera tratarse, con enormes reservas, de $\mathrm{H}$ (BNE, ms. 4260).

El testimonio $\mathrm{E}_{\mathrm{LA}}$ ofrece cuatro variantes: franchas ${ }^{34}$, tallentosas ${ }^{35}$, excotina $^{36}$ e iguales $^{37}$. La lección franchas es la que presentan los mss. E, H y L (BNE, mss. 2970, 4260 y RAH, ms. 9-28-3/5495). Hemos podido documentar tallentosas en J (BNE, ms. 9684). Excotina e iguales no se han localizado en ningún manuscrito. Con tan exiguos materiales no es posible establecer una identificación válida.

En conclusión, a pesar de la negativa de varios críticos a lo largo de la historia y aunque es imposible por el momento identificar el manuscrito de base de la edición de Lafuente Alcántara, es posible identificar algunos de los manuscritos que utilizó para extraer las variantes. Creemos haber demostrado que

29 Ibíd., pág. 42, n. 2.

30 Ibíd., pág. 46, n. 2.

31 Ibíd., pág. 105, n. 1.

${ }^{32}$ La duda viene del hecho de que estas palabras se encuentran en la dedicatoria, que en este manuscrito es una adición realizada el 18 de febrero de 1739 a partir de un manuscrito que se encontraba «en el Gavinete de los Mss. de | la Real Bibliotheca» (BNE, ms. 4260, fol. IVv).

${ }^{33}$ Cummins, ed. cit., pág. 76, n. 9.

${ }^{34}$ Ibíd., pág. 44, n. 1.

35 Ibíd., pág. 90, n. 1.

${ }^{36}$ Ibíd., pág. 98, n. 1.

${ }^{37}$ Ibíd., pág. 22, n. 1. 
el ms. $B_{\mathrm{LA}}$ es el 1464 de la BNE (nuestra B). El testimonio $\mathrm{D}_{\mathrm{LA}}$ es el ms. 4208 del a BNE (nuestra G). Es posible, con cierto margen de error, que el ms. $\mathrm{C}_{\mathrm{LA}}$ sea el ms. 4260 de la BNE (nuestra H). En cambio, en este momento es imposible identificar los mss. $\mathrm{E}_{\mathrm{LA}}, \mathrm{F}_{\mathrm{LA}}, \mathrm{G}_{\mathrm{LA}} \mathrm{y}_{\mathrm{LA}}$ con alguno de los que se conocen en la actualidad.

Por otra parte, es curioso notar que cuando Lafuente Alcántara corrigió el manuscrito $A_{L A}$ lo hizo con la lectura del testimonio $B_{L A}$ : por ejemplo, en «et trabajasen et fiziesen exerçiçio por sus personas et cuerpos», en la nota pertinente aclara que $« \mathrm{~A}$. Omite personas» ${ }^{38}$. Hemos podido comprobar que se trata de una amplificatio exclusiva de los mss. BG. En la tabla inicial, la rúbrica del capítulo XVII lee «Del falcon que tiene el papo e tripas llenas de viento» y en la nota correspondiente se aclara que $« \mathrm{~A}$. Omite $e$ tripas» ${ }^{39}$ : de nuevo la amplificatio es exclusiva de $\mathrm{BG}^{40}$. En la misma tabla, en la rúbrica del capítulo XXXIII se lee «De los falcones que son feridos de aues» $\mathrm{y}$ en la nota a pie de página se nos informa de la lectura de «A. Que ha tropigo et fichaçon» ${ }^{41}$ : lo editado por Lafuente Alcántara es otra la lección exclusiva de BG. En el capítulo VIII, cuando los halcones cometen el error de tratar de capturar una ánade que se ha refugiado en el agua, Ayala ordena «non les des esa ora a comer». Lafuente completó el texto añadiendo «quier mate o non» y en la nota aclara que «A. Omite esta frase» ${ }^{42}$; esta lectura la presentan los manuscritos BGOCc.

Pero no siempre completó Lafuente Alcántara su texto con BG: a veces recurrió a otros de los testimonios utilizados por él. Así, en el primer capítulo, cierra la exposición de los distintos tipos de regímenes alimenticios de las aves con las palabras «de todas las aues las mas limpias son aquellas que solamente se pascen et mantienen de aues biuas» en la nota crítica indica que «A. Omiten [sic] pascen» ${ }^{43}$, que es lectura de $\mathrm{H}$ (fol. 3r).

Esto nos lleva a otra cuestión muy interesante y que demuestra que alguno de los críticos que se han acercado al Libro de la caza de las aves no han estudiado con la demora debida la edición de Lafuente Alcántara, a pesar de que la han utilizado como fuente de variantes. Se trata del problema que plantea el capítulo XLIV, que presenta los alcotanes. Cummins dice «Este capítulo falta en todos los manuscritos. [...] El texto que seguimos aquí es el de la edición de la Sociedad de Bibliófilos Españoles, o sea del MS X» ${ }^{44}$ y en el estema que ofrece indica que tras la producción de $\mathrm{X}$ se realizó un arquetipo en el que fal-

\footnotetext{
${ }^{38}$ Ibíd., pág. 5, n. 2.

39 Ibíd., pág. 8, n. 4.

${ }^{40}$ En O (fol. 4r) tripas está en vez de papo.

${ }^{41}$ Lafuente Alcántara, ed. cit. pág. 5, n. 2.

42 Ibíd., pág. 50 , n. 1.

${ }^{43}$ Ibíd., pág. 19 , n. 3.

${ }^{44}$ Cummins, ed. cit., pág. 191 , n. 1.
} 
tan el colofón y el capítulo $\mathrm{XLIV}^{45}$. Sin embargo, la nota que puso Lafuente Alcántara es clara «Falta este capítulo en los MS. A. D.» ${ }^{46}$. No explicita de dónde la ha tomado, pero solo se conoce un manuscrito que lo contiene: el ms. 1464, fol. 130r ( $\mathrm{B}_{\mathrm{LA}}$, nuestra $\left.\mathrm{B}\right)$. A este testimonio recurrieron MontandonHummel $^{47}$, quien se limitó a indicar que faltaba en su manuscrito de base (British Library, ms. Add. 16392), y Delgado Montoto ${ }^{48}$.

José GutiÉRrez DE lA VeGA. Diez años después (1879) el publicista, político y erudito José Gutiérrez de la Vega editó de nuevo la obra del Canciller en el tercer volumen de la Biblioteca Venatoria Española, juntamente con el Libro de la caza de don Juan Manuel.

En el discurso que antecede a la edición, tras bosquejar una biografía de Ayala $^{49}$ y una escueta relación de sus obras ${ }^{50}$, analiza el Libro de la caza de las $a_{v e s^{51}}$, lo que en realidad se convierte en una fortísima crítica de la edición de Lafuente Alcántara. Se fijó en dos puntos básicos: la inadecuación del título elegido - Libro de las aves de caza - y la inclusión de unas glosas al libro de Ayala atribuidas a Beltrán de la Cueva. Acertaba Gutiérrez de la Vega en sus críticas, por lo que no vamos a insistir en ellas. Lo que nos interesa es cómo editó el texto de Ayala.

Gutiérrez de la Vega, hábil publicista, no declara en ningún momento qué manuscrito de los recopilados en su «Bibliografía venatoria española» ${ }^{52}$ ha utilizado para su edición. Según Jan Nelson empleó el ms. 1464 (olim L-188) de la $\mathrm{BNE}^{53}$. Este investigador basa su afirmación en el hecho de que es el único manuscrito que Gutiérrez de la Vega cita con signatura dentro del estudio y la edición del texto. Lo hizo en dos ocasiones. La primera cuando, tras señalar que la edición que él publica del Libro de la caza de las aves se hace «con el nombre suyo, y sin las glosas, porque no son suyas ${ }^{54}$, aclara que ha incorporado «un Apéndice, especie de recetario para la cura de los halcones, que acompaña al códice de dicha obra, y que con la signatura L.188 se conserva en la

45 Ibíd., pág. 136.

${ }^{46}$ Lafuente Alcántara, ed. cit. pág. 151, n. 1.

${ }^{47}$ Montandon-Hummel, ed. cit., pág. 329.

${ }^{48}$ Delgado Montoto, ed. cit. págs. 445-446.

${ }^{49}$ Gutiérrez de la Vega, ed. cit., págs. xxxi-xxxviii.

${ }^{50}$ Ibíd., págs. xxxix-xli.

${ }^{51}$ Ibíd., págs. xlii-lix.

52 José Gutiérrez de la Vega, «Bibliografía venatoria», en Alfonso XI, Libro de la montería, Madrid, M. Tello, $1877, \mathrm{n}^{\circ} 55-70$ y $218-221$.

${ }^{53}$ Jan Alan Nelson, «A Critical Edition of the Livro de citraria», tesis doctoral, University of North Carolina, 1964, pág. xvii. En su referencia hay un error mecanográfico, y la signatura quedó reducida a L-88.

${ }^{54}$ Gutiérrez de la Vega, ed. cit., pág. lviii. 
Biblioteca Nacional». La segunda mención se encuentra en la nota a pie de página al inicio del apéndice: «Esto es todo lo que trae al final, y como adición al libro de Pero López de Ayala, de la misma letra que el texto en su mayor parte, el codice L. -188 de la Biblioteca Nacional» ${ }^{55}$.

Gutiérrez de la Vega no dice taxativamente que utilizara el ms. L-188 para realizar su edición, sino que en dicho manuscrito, que contiene una copia de la obra de Ayala, figura una serie de recetas para la cura de los halcones que están escritas con el mismo tipo de letra que la copia de Ayala. No dice otra cosa.

Montandon-Hummel ${ }^{56}$ detectó el equívoco en el que cayó Nelson y, aunque no lo demostró, afirmó que la edición de Gutiérrez de la Vega es una simple reproducción de la de la Sociedad de Bibliófilos Españoles con la ortografía modernizada.

Una somera comparación entre la invocación y el inicio del prólogo de la edición de Lafuente Alcántara y la de Gutiérrez de la Vega muestran el grado de modernización que presenta la edición de éste:

\section{Lafuente Alcántara \\ CRISTUS ADSIT NOBIS GRATIA}

En el nonbre del padre et del fiio et del espíritu sancto amen. Dize et amonéstanos el apóstol que todas las cosas que auemos de fazer fagamos en el nonbre del señor, porque todo don bueno é acabado dél viene, et sin él non puede ser fecha cosa alguna. Et por ende, llamando la su ayuda et gracia, començaré vna pequeña obra para exercicio de los ombres, por los tirar de oçio et pensamientos, et puedan auer entre los sus enojos et cuydados algund plazer et recreamiento sin pecado; la qual obra será un pequeño escripto, en que departirá de la caça de las aues et de sus plumajes et dolençias et melezinamientos.

Al muy honrrado padre é señor don Gonçalo de Mena, por la gracia de Dios obispo de la muy noble çibdat de burgos, Pero Lopes de ayala, vuestro homil pariente et seruidor, me encomiendo en

\section{Gutiérrez de la Vega CRISTUS ADSIT NOBIS GRATIA}

En el nombre del padre et del fijo et del Espíritu sancto amen. Dice et amonéstanos el Apóstol que todas las cosas que habemos de facer fagamos en el nombre del Señor, porque todo don bueno é acabado dél viene, et sin él non puede ser fecha cosa alguna. Et por ende, llamando la su ayuda et gracia, comenzaré una pequeña obra para ejercicio de los hombres, por los tirar de ocio et pensamientos, et puedan haber entre los sus enojos et cuidados algund placer et recreamiento sin pecado; la cual obra será un pequeño escripto, en que departirá de la caza de las aves et de sus plumajes et dolencias et melecinamientos.

\section{Prólogo}

Al muy honrado Padre é Señor don Gonzalo de Mena, por la gracia de Dios Obispo de la muy noble cibdat de Burgos, Pero Lopes de Ayala, vuestro homil pariente et servidor, me enco-

\footnotetext{
55 Ibíd., pág. 345, n. 1.

${ }^{56}$ Montandon-Hummel, ed. cit., pág. 426, n. 42.
} 
la vuestra merced. Señor, dize el filósofo Aristóteles en el otauo libro de las éticas en la filosofia moral, que á los verdaderos amigos de buena et honesta amistança non los departe la distançia de lugares; que quiere dezir que por estar los omes amigos verdaderos alongados uno de otro é arredrados por luenga tierra, la verdadera é honesta amistança non se departe de entre ellos, antes está et dura firme en su virtud. E señor, gran tiempo há que fuy et só alongado de vuestra presençia é vista por luengo apartamiento de tierra, empero sienpre la vuestra buena et verdadera et onesta amistança touo siempre en mi toda su virtud $[\ldots]^{57}$. miendo en la vuestra merced. Señor, dice el filósofo Aristóteles en el otavo libro de las Eticas en la Filosofia Moral, que á los verdaderos amigos de buena et honesta amistanza non los departe la distancia de lugares; que quiere decir que por estar los homes amigos verdaderos alongados uno de otro é arredrados por luenga tierra, la verdadera é honesta amistanza non se departe de entre ellos, antes está et dura firme en su virtud. E señor, gran tiempo há que fuí et só alongado de vuestra presencia é vista por luengo apartamiento de tierra, empero sienpre la vuestra buena et verdadera et honesta amistanza tovo siempre en mí toda su virtud $[\ldots]^{58}$.

Aunque profundizáramos en el texto, salvando la modernización ${ }^{59}$, no veríamos muchos más cambios.

Si lo comparamos con el texto del ms. 1464 de la BNE, pronto saltan a la vista unas cuantas variantes de sustancia que demuestran que Gutiérrez de la Vega no usó este manuscrito, como pretendía hacernos creer. La primera es la invocación en latín, que no se encuentra en el manuscrito aducido. Después tenemos que buena et honesta amistanza en B es buena e leal amistad; un poco más adelante estar los homes amigos no es como aparece en $\mathrm{B}$, donde se lee estar los amigos; o de nuevo la lección amistanza de la edición de Gutiérrez de la Vega es amistad en B. De menor interés, porque las podemos considerar meras variantes de lengua, es el que B lea ciudad y octavo y la edición de Gutiérrez de la Vega edite cibdad y otavo.

Frente a los pasajes en los que es evidente que Gutiérrez de la Vega reprodujo la edición de Lafuente Alcántara, a veces, sin embargo, trató de solventar las complicaciones con las que se encontró el primer editor del texto de Pero López de Ayala.

Uno de los conflictos se encuentra en el capítulo VI, de los borníes. Aquí Ayala describe una variedad muy peculiar de Asturias, a la que llaman tagre.

\footnotetext{
${ }^{57}$ Lafuente Alcántara, ed. cit., págs. 1-2.

${ }^{58}$ Gutiérrez de la Vega, ed. cit., págs. 139-142.

${ }^{59}$ Convierte la $<$ ç $>$ en $<\mathrm{c}>$ ante vocal palatal y en $<\mathrm{z}>$ en los demás casos, la $<\mathrm{z}>$ seguida de $<$ e, i $>$ pasa a $<\mathrm{c}>$; simplifica la $<\mathrm{rr}>$ postconsonántica; regulariza el uso de $<\mathrm{u}>,<\mathrm{v}\rangle$ (seruidor $>$ servidor; touo $>$ tovo) y corrige $\mathrm{a}<\mathrm{b}>$ cuando las reglas ortográficas los exigen (auer $>$ haber); restituye, salvo en algunas palabras como fijo o facer (y toda su flexión) la $<\mathrm{h}\rangle$ : ome $>$ home; onesta $>$ honesta.
} 
Después de contar que el rey don Pedro tuvo uno de estos pájaros, recuerda que vio «un falcon borrny ... torçuelo al obispo de leon don diego ramirez de guzman» ${ }^{60}$. En los puntos suspensivos el editor remite a una nota a pie de página en la que da cuatro lecturas «A. Prima. B. Premia. C. Primo. D. Primero.» Lafuente Alcántara no supo resolver la cuestión porque un borní prima torzuelo, es decir, un halcón 'hembra macho', es algo físicamente imposible. Gutiérrez de la Vega eliminó los puntos suspensivos e imprimió «falcón borní torzuelo» ${ }^{61}$. De los treinta y cinco testimonios que conocemos tan sólo cuatro - $\mathrm{CCcHO}$ - presentan la lectura borní prima torzuelo; la mayoría lee prima tuerto $^{62}$, que tiene que ser la lectura arquetípica (en este caso del original).

Pero Gutiérrez de la Vega no quiere dar la sensación de que su edición es una copia de la que él ha criticado ferozmente, por lo que se permite incluir tres notas en las que corrige la edición de Lafuente Alcántara ${ }^{63}$. Se trata de nimiedades que se pueden enmendar ope ingenii, que es exactamente lo que Gutiérrez de la Vega hizo. La corrección de las páginas 145 y 213 consiste en imprimir la conjunción et donde Lafuente Alcántara imprimió es y el respectivamente; en la página 210 corrige la repetición de uno. Nimiedades.

Por tanto, y contrariamente a lo que se venía sosteniendo, la edición de Gutiérrez de la Vega no es más fiable que la de Lafuente Alcántara. Es más, podría afirmarse que la edición de Lafuente Alcántara es de mayor valor. Mientras que Gutiérrez de la Vega se limita a copiar el texto de Lafuente Alcántara y modernizar las grafías, en ocasiones Lafuente Alcántara argumenta algunas de sus lecciones y fija el texto aunque no siempre explica su selección ${ }^{64}$.

José Fradejas LeBRero. De la edición de Gutiérrez de la Vega surgirá una tercera edición que ha sido la que mayor difusión ha tenido. Nos referimos a la que preparó José Fradejas Lebrero ${ }^{65}$, una edición en la que se moderniza la

${ }^{60}$ Lafuente Alcántara, ed. cit., pág. 32.

61 Gutiérrez de la Vega, ed. cit. pág. 180.

${ }^{62} \mathrm{~L}$ y W leen prima cuero.

${ }^{63}$ Gutiérrez de la Vega, ed. cit. págs. 145, n. 1, 210, n. 1 y 213, n. 1.

${ }^{64}$ La Biblioteca Virtual Cervantes (http://www.cervantesvirtual.com/ [consulta 04.05.2010]) recoge una edición digital del Libro de la caza de las aves «a partir de la de José Gutiérrez de la Vega» (http://www.cervantesvirtual.com/servlet/SirveObras/01482307212363781870035/index.htm [consulta 04.05.2010]) «cotejada con la versión de José Fradejas Lebrero (Madrid, Castalia, Col. Odres Nuevos, 1969), cuyos criterios seguimos en la mayoría de los casos». Incluye, además, una concordancia (http://www5.cervantesvirtual.com/cgi-bin/cgiconcordancias?ref=001674). Recientemente se ha incorporado una versión en formato epub entre los libros que regala el lector Papyrus (http://www.grammata.com [acceso 04.05.2010]) (Libro de la caza de las aves. López de Ayala, Pedro.epub de 197 KB).

${ }^{65}$ Pero López de Ayala, Libro de la caza de las aves, cit. Desde 1969 se reimprime, siempre como segunda edición, pero con cambio del año (la última está datada en 1993). 
lengua, pero sin llegar a una actualización total. Aunque desde el punto de vista textual no supone ningún avance con respecto a las ediciones decimonónicas, su gran aportación consiste en marcar en cursiva todo aquello que Ayala tomó del Livro de falcoaria de Pero Menino ${ }^{66}$ y haber sido el gran divulgador de la obra de Ayala ${ }^{67}$.

MAdElaine Montandon-Hummel. Cuando se cumplía el sexto centenario (1986) de la finalización de la redacción del Libro de la caza de las aves, la investigadora helvética Madeleine Montandon-Hummel presentó una nueva edición del tratado ayalino como tesis doctoral. Montandon-Hummel limitó su investigación a los manuscritos del siglo XV de los que ella tenía noticia - AHMNO_. Aunque en su trabajo recoge otros dieciséis, todos ellos de siglos posteriores, se sirvió unicamente del ms. 1464 de la BNE, del que extrajo el capítulo de los alcotanes, que no se encuentra en ningún otro testimonio. A la luz de los demás testimonios reorganiza los folios del manuscrito de base (BL, Add. 16392), sin explicar el motivo por el que esos folios se encuentran descolocados.

$\mathrm{Su}$ interés desde el punto de vista ecdótico se limita a la discusión del título de la obra - propuso el poco individualizante de Libro de cetrería porque «lo llevan nueve códices y sólo cuatro el de Libro de la caça» $^{68}$ - y la puesta en duda la veracidad del colofón que presentan todas las ediciones que le han precedido.

John G. Cummins. John Cummins también se ciñó a los manuscritos del cuatrocientos, si bien amplió el elenco de las copias del siglo XV (AHMNO) con dos manuscritos conservados en los Estados Unidos de América (TU). Además tuvo una mayor amplitud de miras al incorporar otros testimonios más modernos (FILS). También tuvo en cuenta la edición de Lafuente Alcántara, que incorporó como un testimonio más y que designa con la sigla $\mathrm{X}$.

Cummins trató de establecer una genealogía de los manuscritos basándose en seis criterios:

1) Unificación del Libro de la caza de las aves con la obra de Juan de Sahagún.

2) Manuscritos cuya copia se origina en Nápoles.

3) Manuscritos con conexión italiana.

4) Influencia lingüística del aragonés o del catalán.

5) Materia adicional incluida al final.

6) Las variantes.

${ }^{66}$ Cummins, ed. cit., también destaca lo que procede de Menino, pero de una manera más imprecisa, puesto que mediante marcas en los márgenes indica dónde comienza y dónde finaliza la materia traducida del portugués.

${ }^{67}$ Véase lo dicho en la nota 63 acerca de las ediciones digitales del Libro de la caza de las aves.

${ }^{68}$ Montandon-Hummel, ed. cit., pág. 424, n. 26. 
Con el primer criterio reunió en una misma familia los manuscritos EFT. También vio que $\mathrm{E}$ no sirvió de fuente a $\mathrm{F}$ «puesto que faltan en $\mathrm{E}$ varios capítulos que figuran en $\mathrm{F}_{»}{ }^{69}$. Sin embargo, erró al afirmar que en $\mathrm{F}$ no se encuentra la laguna que es patente en $\mathrm{T}$ ni indica en las notas críticas lo que falta en T. De hecho, esta laguna está presente en todos los testimonios de esta familia, tanto en E, que no analizó en detalle, como en FT.

Respecto al segundo criterio, es acertada la agrupación de $\mathrm{H}$ y $\mathrm{C}$, que descienden de la copia que realizó Jiménez López en Nápoles «la biespra de todos santos [...] Anyo mcccc xlvi» (ms. H, fol. 73r). Sin embargo, dentro de esta conexión napolitana le resulta imposible situar $U$, manuscrito realizado, según todos los indicios, en Nápoles para la familia real de Aragón.

El tercer criterio le permite relacionar A con los testimonios napolitanos - CHU - por la «alusión a un antiguo poseedor» — «Ex codicibus Joannis Angelis | Ducis ab altaemps» (fol. 86r) — y por el título de la obra — «Della natura de falconi» (fol. 1) y «Della natura de falconi | et altri uccelli da caccia | in lingua spagnoula» (fol. 86r)_. Alega la existencia de «unas pocas variantes particulares que parecen revelar una posible familiaridad con el italiano por parte del copista» ${ }^{70}$, pero sin indicar de cuáles se trata.

En el cuarto criterio agrupa los manuscritos que revelan rasgos lingüísticos aragoneses o catalanes. Tienen esta coloración los manuscritos CHILU. En el caso de $\mathrm{H}$ la filiación linguiística queda patente en la suscripción de propiedad «Don Gaspar Galcerán de Gurrea i Aragón» (portada). Cummins atribuye el orientalismo lingüístico de CHU a «la conexión con Nápoles». También se incluyen en este apartado A y M, que «emplean algún leve aragonesismo» ${ }^{71}$.

El quinto criterio es del mismo tipo que el primero: la existencia de otros textos en los manuscritos. Según sus observaciones, los testimonios CFHLT presentan a continuación de la obra de Ayala el Libro de la condición natural y de la fermosura del açor y esparver, un breve tratado de quince capítulos cortos. CHL también contienen Los capitoles de las suertes de los falcones ${ }^{72}$. Añade un tercer eslabón «ciertas recetas independientes incluidas en el mismo orden al final del capítulo XLVII en los MSS D, I y K» ${ }^{73}$.

El sexto criterio, que se fija en las variantes, le permite establecer tres agrupaciones: $\mathrm{CH}$, FT y AMU. Para los dos primeros grupos ( $\mathrm{CH}$ y FT) remite a lo dicho en los criterios 1 y 2 . En el caso del grupo FT señala que en T existen varias lagunas no reproducidas en $\mathrm{F}$, afirmación que, como hemos comprobado, no se sostiene. Para $\mathrm{CH}$ no hay evidencia de variantes, pero $\mathrm{H}$ presenta aragonesismos

\footnotetext{
${ }^{69}$ Cummins, ed. cit., pág. 34.

${ }^{70}$ Ibídem.

${ }^{71}$ Ibídem.

${ }^{72}$ L solo tiene la tabla.

73 Ibíd., pág. 33.
} 
que son corregidos en C. La tercera agrupación (AMU) se basa en el hecho de que AM remiten, al final del capítulo XX, a un remedio que se ha explicado en el capítulo XI y que se encuentra en «fojas .xl.». Es un indicio precioso porque ningún manuscrito de los manejados por Cummins presenta el capítulo XI en el folio .xl.; luego esa lectura debe proceder del antecedente común a AM, que es la conclusión a la que él mismo llega: «deben derivarse los dos de un manuscrito más antiguo» ${ }^{74}$. También localizó una enmienda a esta remisión en el ms. L, que remite a «foja xxxvii». Este manuscrito «a veces tiene un texto bastante parecido a A y M, pero ... también tiene variantes muy especiales y omite muchas palabras y expresiones que el copista considera superfluas» ${ }^{75}$. Asimismo vio algunas variantes exclusivas de A y U, pero llega a la conclusión de que U no es el antígrafo de A. Incluso le parece más probable lo contrario, es decir, que A sea la fuente de U, aunque en A se documenta una serie de variantes que no se encuentran en U. En definitiva, concluye que ambos tienen un antecedente común.

Cummins resumió sus observaciones en el siguiente estema ${ }^{76}$

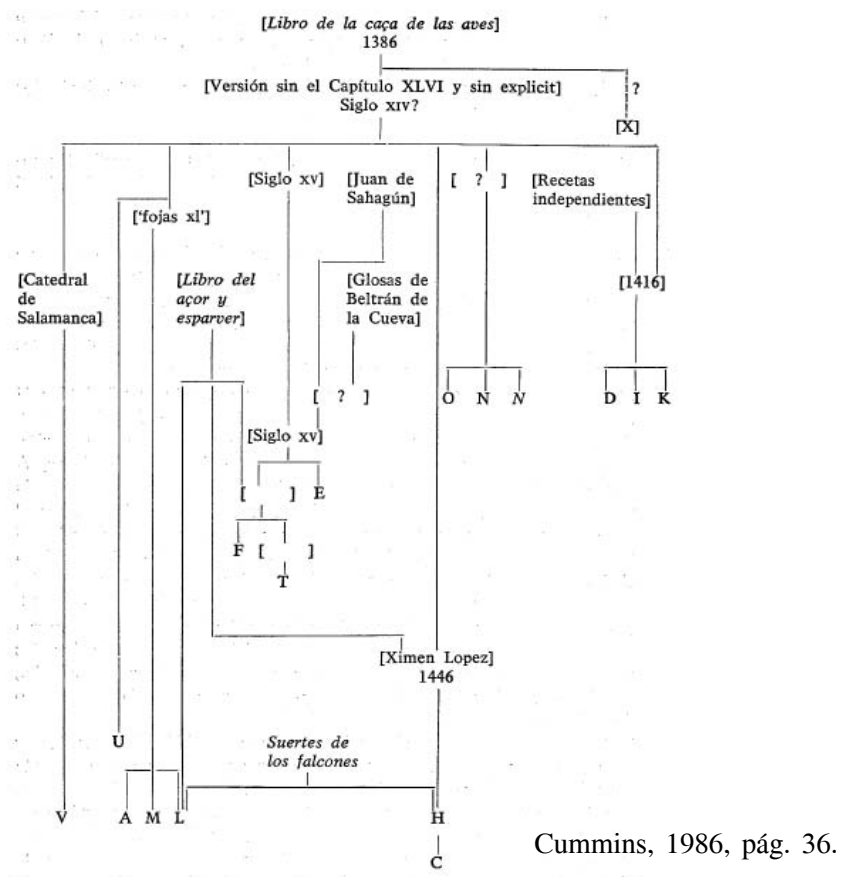

que precisa de una explicación que no ofrece.

\footnotetext{
${ }^{74}$ Ibíd., pág. 35.

75 Ibídem.

${ }^{76}$ Ibíd., pág. 36.
} 
Nuestra lectura del estema es la siguiente: tras la redacción de 1386 se hicieron dos copias: una de la que descendería X (el antígrafo de Lafuente Alcántara) y otra en la que se omitió el capítulo de los alcotanes (cap. XLIV -XLVI en el estema de Cummins_-) y el colofón ${ }^{77}$. De este arquetipo derivan seis familias con diferente número de elementos: 1) V, 2) UAML, 3) EFT, 4) $\mathrm{HC}$, 5) $\mathrm{ONN}{ }^{78}$ y 6) DIK. Restan ocho testimonios (BGIJPQRS) ${ }^{79}$ que no pudo introducir en el esquema.

La primera línea de descendencia se conforma porque el ms. V es copia de otro que existía en la Catedral de Salamanca y del que hoy no queda rastro, si bien se conservaba todavía en $1652^{80}$.

La segunda tiene un fuerte argumento que permite reunir todos aquellos testimonios que de una u otra manera remiten desde el capítulo XX al folio correspondiente del capítulo $\mathrm{XI}^{81}$. Pero da a entender que la referencia interna es una innovación del grupo AML, cuando parece mucho más factible que la innovación sea la eliminación de dicha referencia en $\mathrm{U}$ y en el resto de los testimonios.

La tercera familia (EFT), que se basa en la unificación del Libro de la caza de las aves con el tratado de Juan de Sahagún, es correcta. Lo que es erróneo

${ }^{77}$ El colofón publicado por Lafuente Alcántara dice: «Aquí se acaba el libro de la caça de las aues, que fizo | pero lopez de ayala en el castillo de ouiedes en | portogal, en el mes de junio, año del | Señor de mill et trezientos et ochenta | y seys años, era de çésar de | MCCCCXXIIII años» (pág. 167). Montandon-Hummel (ed. cit., pág. 8) ponía serios reparos a la autenticidad del explicit, aunque «siempre pueden descubrirse nuevas copias desconocidas». Afortunadamente, apareció, un año después, la copia que demostraría que no era una falsificación entre los anaqueles del coleccionista francés Marcel Jeanson. Desgraciadamente, no se trataba del códice que pudo ser propiedad del conde de Altamira puesto que no está escrito sobre pergamino y, además, presenta fuertes variantes: «II Aqui se·acaba el libro | de·la caça de·las aues \& fue | fecho \& acabado en·el casti|llo de avidos en porto|gal en $e l$ mes de junio | año de jv trezientos ||$\&$ ochenta \& seys años | Era de jv $\operatorname{cccc}$ xxxiiij $^{\circ} \mid$ años» (ms. Bb, fol. 80r-v).

${ }^{78} \mathrm{~N}$ y $N$ son dos copias que se encuentran reunidas en un mismo códice, el ms. II-1370 de la Biblioteca Real de Madrid. En nuestra tabla y argumentación, para evitar los problemas que supone la diferenciación por cambio de fuente, la copia $N$ (en cursiva) se identifica como $\mathrm{N}_{1}$.

${ }^{79}$ Hay que analizar con un poco de detenimiento el caso de I. Aunque afirma que no ha podido ubicarlo en el esquema, lo inserta en el grupo DIK, que tiene un antígrafo fechado en 1416.

${ }^{80}$ Otra mención a la existencia de un manuscrito en la catedral salamantina se encuentra en el ms. P: «Este libro dizen que le conpuso D. Alonso | de Madrigal el Tostado; no es sino | de D. Pedro Lopez de Ayala, el que escribio | la Historia del Rey D. Pedro i le | tengo original el que tenia en su libreria | la S. Iglesia de Salamanca. | El del obispo D. Alonso de Madrigal no le | he podido descubrir, i este consta que le | hizo D. Pedro Lopez de Ayala, del original que yo tengo i refiero. Escribi esto | en v. de Agosto de 1652» (ms. P, fol. 2r). Recientemente (abril 2010) hemos localizado un tercer manuscrito, que marcamos como $\mathrm{Hh}$, que declara taxativamente que es copia del ejemplar que había en la biblioteca catedralicia. Dice la portada caligráfica: «Libro $\mathrm{d} e$ ce|treria fecho por pe|dro lopez de ayala caça|dor del Rey don pedro | acabose de trasla|dar en salamanca | sabado. a .xxij. de | mayo año de . | ju d xxxv | años. | Sacose del original que esta en la li|breria de la yglesia mayor de la dicha çibdad» (ms. Hh, fol. Ir).

${ }^{81} \mathrm{El} \mathrm{ms}$. Bb, localizado con posterioridad a la edición de Cummins, también remite a «foja $\mathrm{xl}$ (ms. Bb, fol. 44r). 
es relacionar el Libro del açor y esparver con L y los derivados de la copia de Jiménez López $(\mathrm{CH})$. El Libro del açor y esparver de FT es una copia parcial del llamado Libro de los azores que se conserva en el ms. V.II.19 de El Escorial $^{82}$, mientras que lo que se encuentra en CHL es otro texto breve cuyo incipit dice $^{83}$ :

$\mathrm{C}$

Aqui habla de la condizion natural y | de la fermosura del azor esparuer compli|mjento y enfermedad de diuersas medizinas de A|zor y esparuer (fol. $95 \mathrm{v})$
$\mathrm{L}$

Aqui faula de la condicion natural y de la for|mosura del açor y esparuer complimiento y en|fermedad de diuersas medecinas de açor y esparuer (fol. 71v)

\section{$\mathrm{H}$}

Aqui habla de la condiçion natural y de la fermosura | del açor y esparuer conplimiento y enfermedad de | diuersas medeçinas de açor y esparuer (fol. 70r)

De esta parte del estema también se desprenden dos hipótesis: primero, que el antecedente común inmediato de FT, representado con un espacio en blanco entre corchetes en el estema, debió de añadir los capítulos que faltan en E; y, segundo, que en el antecedente de $\mathrm{T}$ (espacio en blanco entre corchetes en el mismo estema) se debió de originar la laguna que constituyen «una serie de renglones incompletos en el fol. 113 de T, que debe indicar un folio roto en su fuente, donde $\mathrm{F}$ tiene el texto completo» ${ }^{84}$. Para facilitar las explicaciones extraemos el estema de la familia EFT y aclaramos los códices interpuestos con $\alpha$ y $\beta$ :

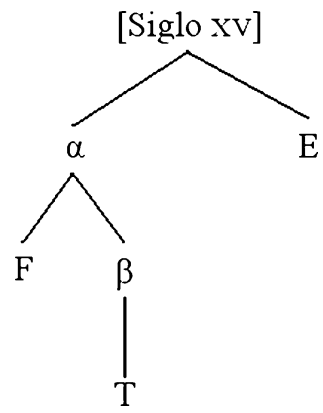

Nuestra lectura del subestema propuesto por Cummins es la siguiente: en [Siglo XV] se recogieron en un mismo manuscrito las obras de Ayala y

82 José Manuel Fradejas Rueda, Antiguos tratados de cetrería castellanos, Madrid, Cärel, 1985, págs. 93-105.

${ }^{83}$ A esta serie hay que añadir el manuscrito $\mathrm{W}$, que Cummins no mencionó en su catálogo, quizá por tratarse de una copia del siglo XVIII. W es un codex descriptus de L, por tanto inútil para la filiación de los testimonios. 
Sahagún. Pero el ejemplar de la obra de Ayala que se utiliza es una copia incompleta ya que $\mathrm{E}$ se nos presenta como un descendiente directo de [Siglo XV] y sabemos que a E le faltan los capítulos XVI, XXIII, XXVIII y XXXI-XLVII. En el mismo siglo se hace otra copia $(\alpha)$ en la que se soluciona el problema de las omisiones textuales de E con el recurso a otro manuscrito del que no tenemos noticia. Este testimonio $\alpha$ se conservará hasta el siglo XVII cuando se realiza la copia F. A su vez, en el mismo siglo XV, se hace la copia $\beta$, en el que se producirá un roto $^{85}$ que da lugar a la laguna que encontramos en $\mathrm{T}$.

De entrada, creemos que es altamente improbable cuando no imposible que $\alpha$ pudiera reconstruir lo omitido por $\mathrm{E}$.

Pero el primer gran fallo, que pone en tela de juicio el trabajo de Cummins, es no haber hecho la collatio de FT y E. En todo el aparato crítico de Cummins no se recoge ni una sola variante de E. No lo examinó con el detalle debido porque cumple tres de las cuatro condiciones que le sirvieron para no tener en cuenta un manuscrito ${ }^{86}:$ 1) fecha tardía, 2) estado incompleto y 3) estado destrozado. El cuarto, «corrupción de su texto» no lo pudo establecer porque no pasó ninguno de los tres exámenes anteriores: 1) es del $\mathrm{XVI}^{87}, 2$ ) está incompleto al faltar los capítulos XVI, XXIII, XXVIII y XXXI-XLVII y 3) está fuertemente afectado por la corrosión de las tintas, lo que hace muy penosa la lectura.

El examen que nosotros hemos hecho de la familia EFT, motivado por el descubrimiento de un nuevo testimonio (Y), revela otra historia muy diferente, que podemos resumir en el siguiente estema:

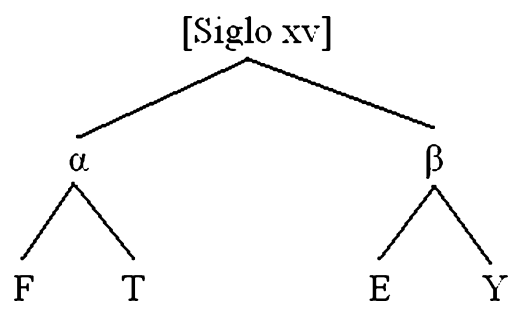

${ }^{84}$ Cummins, ed. cit., pág. 34.

${ }^{85}$ Creemos que más que un roto en el antecedente de esta familia, lo que debió de suceder fue un accidente con algún líquido (quizá el tintero) que provocó la absoluta ilegibilidad de una pequeña zona del exemplar. Nos inclinamos por este tipo de accidente y no un roto (o agujero) en la materia escriptoria por el simple hecho de que el texto que precede o sigue al vacío, a la altura correspondiente, bien del recto bien del vuelto, no presenta una ruptura del sentido que hiciera pensar en un agujero o roto.

${ }^{86}$ Cummins, ed. cit., pág. 37.

${ }^{87}$ En sus fechaciones relativas Cummins lo data en el XV-XVI, pero estas dataciones fueron realizadas con cierta ligereza. Ponemos por ejemplo la del testimonio I. De este manuscrito nos dice Cummins que «los fols. 1-38 van escritos en una letra del siglo XV (?), y los 39-fin en una letra del siglo XVI» (ed. cit., pág. 26). Aunque la letra de los 38 primeros folios pueda pare- 
Concordamos con Cummins en que un elemento básico de esta familia es la reunión en un mismo códice, esto es, un conjunto de folios encuadernados en una misma unidad física, de las obras de Pero López de Ayala y Juan de Sahagún. También aceptamos que FT tienen un antecedente común inmediato diferente al de $\mathrm{E}$ porque en $\mathrm{E}$ faltan varios capítulos. Ahí finalizan nuestras coincidencias.

Contrariamente a lo que afirma Cummins, $\mathrm{F}$ comparte con $\mathrm{T}$ la laguna del folio 113 (cap. XI), aunque F, salvo en dos casos, no ha dejado trazas físicas de la laguna que debía de existir en su antecedente. Veamos el detalle de esos renglones en el ms. T:

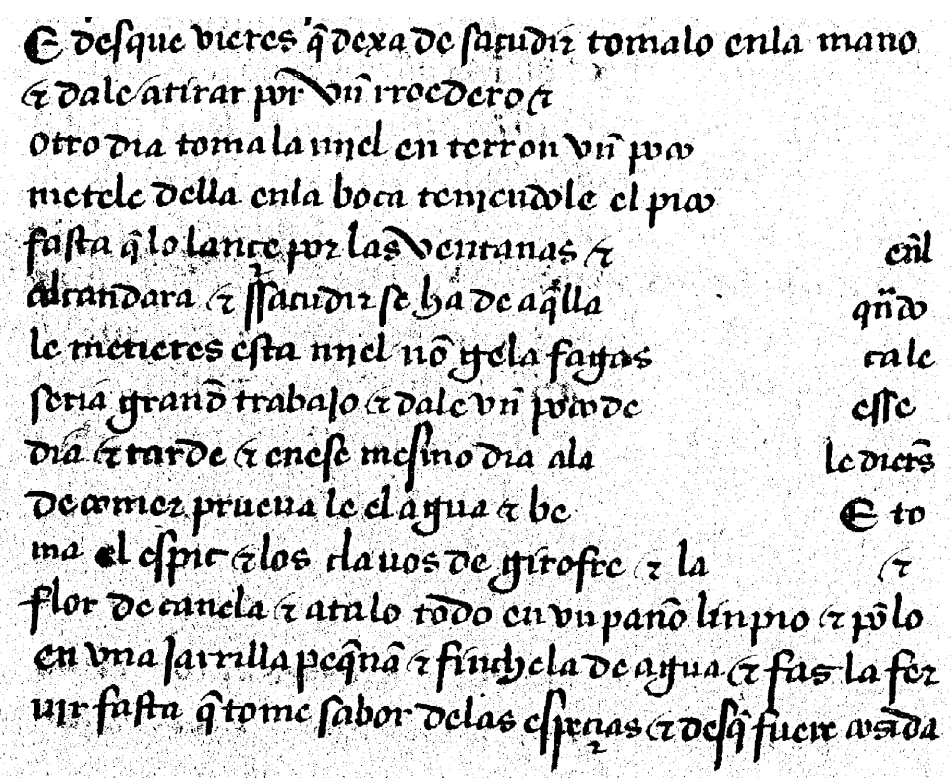

T: New Haven, Beinecke Library, ms. 138, fol. 113r

En el ms. F el pasaje correspondiente se encuentra a caballo entre los folios $184 \mathrm{v}$

\footnotetext{
cer del siglo $\mathrm{XV}$, habría tenido que desechar inmediatamente esta impresión si se hubiera tenido en cuenta la dedicatoria que un personaje no identificado hace «Al ylustrisimo señor don Manrrique de Lara, duque de Nágera, conde de Ualencia, conde de Treuiño, etc.». Los Manrique de Lara, duques de Nájera desde el 30 de agosto de 1482 por concesión de los Reyes Católicos, son condes de Valencia de Don Juan desde 1529, año en el que Juan Esteban Manrique de Lara, III duque de Nájera, se casó con Luisa de Acuña, V condesa de Valencia de Don Juan. Por tanto, la copia del manuscrito tiene que ser posterior a 1529, es decir, ya bien entrado el siglo XVI.
} 


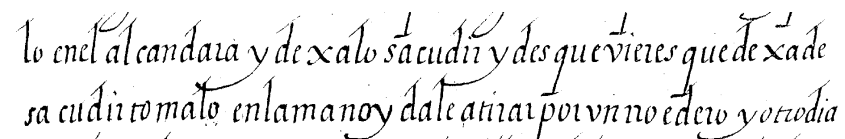
toma lamiel enreuon vnpoco mereledella enlaboca renion doledpio falta guelo lane poulas ventanas yenctalcandara y sacudinseade aquelta quando te merieres eftamiel nongela fagas catesena grannaua Io y date vnpow de esedia y rande yenesc mesmodia quededienes deco

F: Madrid, BNE, ms. 3350, fol. 184v

y $185 \mathrm{r}:$

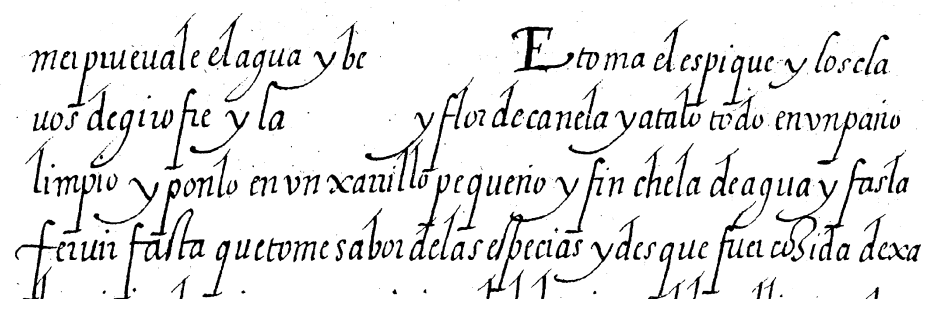

F: Madrid, BNE, ms. 3350, fol. 185r

En el primer fragmento de F (fol. 184v) no hay, aparentemente, laguna alguna. En el segundo (fol. 185r), en cambio, es evidente el hueco que existe en las dos primeras líneas. Algo debería ir detrás de be y entre y la e y flor. El fragmento de F no carece totalmente de sentido; sin embargo, algo disuena. Veamos ahora el texto editado por Cummins:

[...] e desque vieres que dexa de sagudir, tomalo en la mano e dale a tirar por un roedero e a desplumar. Otro día toma la miel en terron un poco dura, e mete della en la boca, e despues que gelo dieres atapale la boca teniendole el pico con la mano, fasta que lo lance por las ventanas, e despues ponlo en el alcandara e sacudirsea de aquel agua. E [quando] le metieres esta miel, non gelo fagas yr al vientre, ca le seria gran trabajo. E dale vn poco de comer esse dia e tarde, e en esse mesmo dia a la tarde, desque le dieres de comer, pruevale el agua e beva della sy quisiere. E toma el espic e los clavos de girofle e la canela e flor de canela, e atalo $[\ldots]^{88}$

Todo lo marcado en negrita falta en FT, aunque en ningún momento Cummins lo menciona en las notas críticas; tan solo aclara unas simples varian-

${ }^{88}$ Cummins, ed. cit., págs. 107-108. 
tes de lengua, sin valor estemático alguno ${ }^{89}$. Por tanto, FT se remontan a un antecedente común inmediato que llamamos $\alpha$. Lo que no podemos establecer por ahora es si FT son descendientes directos de $\alpha$ o si existen otros arquetipos intermedios entre FT y $\alpha$.

Tal y como ya hemos indicado, Cummins no examinó E con el detenimiento necesario, por lo que no descubrió que E también presenta la misma laguna que existe FT. Veamos el fragmento en E:

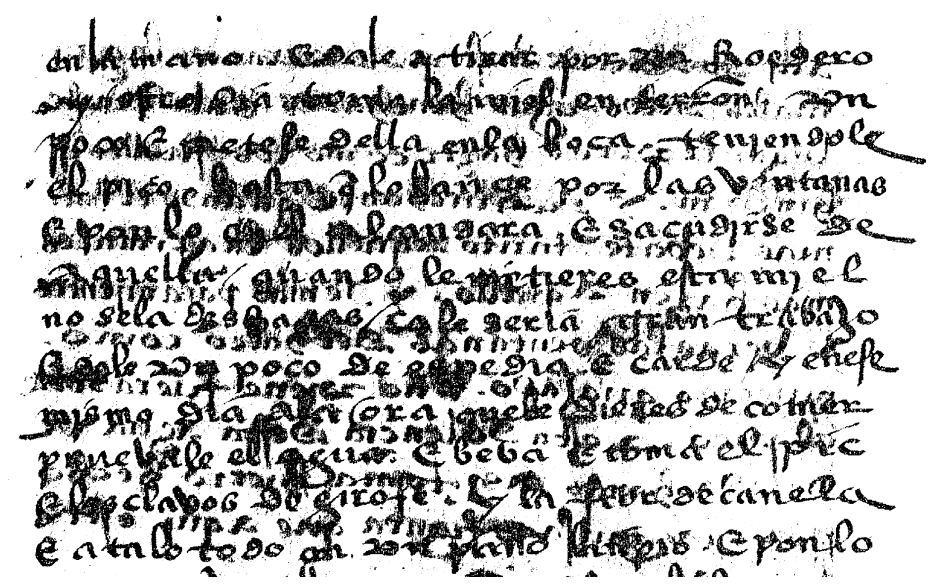

E: Madrid, BNE, ms. 2970, fol. 159r

Está bastante estropeado por culpa de la corrosión de las tintas, uno de los motivos por los que Cummins desechó varios manuscritos. A primera vista no parece haber laguna alguna y, sin embargo, existe. Dado el estado del testimonio, facilitamos la transcripción:

[...] y de que vieres que dexa de sacudjr tomale $\|$ en la mano e dale a tirar por vn Roedero | y otro dia toma la miel en terron vn | poco e metele della enla boca tenjendole | el pico hasta que lo lance por las ventanas | e ponlo en el alcandara e sacudirse de | aquello quando le metieres esta mjel | no se la deshagas ca le seria gran trabajo / e dale vn poco de e*pe dia e carde y en ene | mismo dia a la ora que le dieres de comer | pruevale el agua e beba e toma el espic | e los clavos de girofe y la flor de canela | e atalo [...]

De aquí se deduce que el copista de E, o su antecedente, trataron por todos los medios de arreglar el pasaje para que tuviera sentido. Esto demuestra que E, en

${ }^{89} \mathrm{El}$ mete della de su texto de base aparece como metele della en FNOT. FNT leen aquella agua y no aquel agua. F lee espique mientras que el testimonio de base y $\mathrm{T}$ leen espic. FNT dicen girofre mientras que su modelo dice giroflé. En definitiva, variantes sin valor alguno. 
última instancia, se remonta a un antecedente común a $\mathrm{F}$ y $\mathrm{T}$ : el marcado en el estema como [Siglo XV].

A este grupo de tres manuscritos hay que añadir el ms. 17 de la Biblioteca Statale di Montevergine, que localizamos en febrero 2007 y al que hemos asignado la sigla $\mathrm{Y}^{90}$. Se trata de una copia del siglo XVI que en principio puede parecer distinta a las anteriores puesto que faltan la invocación, la carta-dedicatoria y el prólogo, es decir, todos los preliminares que preceden a la tabla de capítulos. Sin embargo, si no se tienen en cuenta estos elementos, pronto se pone en evidencia que la versión de Ayala que recoge este manuscrito se remonta al mismo antecedente común de EFT. La prueba estemática básica se encuentra en la laguna que detectó Cummins en $\mathrm{T}$, que no vio en $\mathrm{F}$ y que no analizó en E. El manuscrito Y, al igual que T, trató de mantener el hueco. Veamos el fragmento del manuscrito:

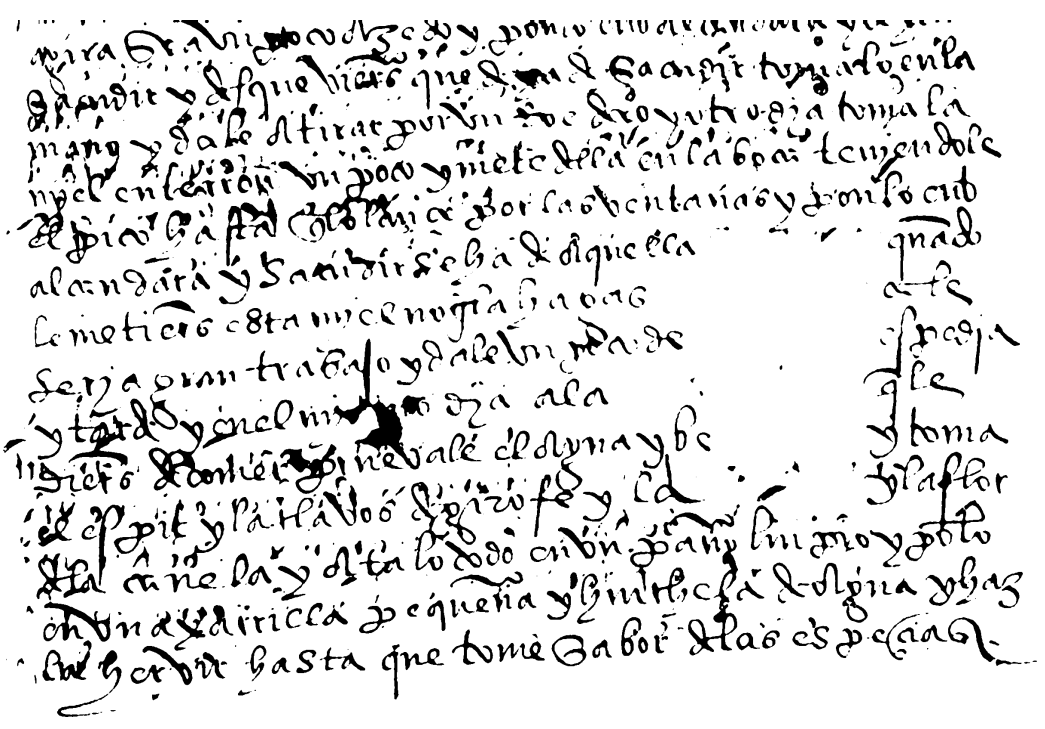

Y: Mercogliano, Biblioteca Statale de Montevergine, ms. 17, fol. 108r

y su transcripción:

[...] y desque vieres que dexa de sacudir tomalo en la $\mid$ mano y dale a tirar por vn Roedero y otro dja toma la $\mid$ mjel en terron vn poco y mete della en la boca tenjendole | el pico hasta que lo lançe por las ventanas y ponlo en $e$ l | alcandara y sacudirse ha de aquella ... quando | le metieres esta mjel no

\footnotetext{
${ }^{90}$ Para una descripción de este manuscrito véase Fradejas Rueda, «De nuevo sobre...», cit., págs. 1102-1104.
} 
gela hagas ... a le | serja gran trabajo y dale vn poco de ... espedia $\mid$ y tarde y en el mjsmo dia a la ... que le | dieres de comer pruevale el agua y be... y toma $\mid$ el espit y latlavos (?) de girofe y la ... y la flor $\mid \mathrm{d} e$ la canela y atalo [...] (fol. 108r).

Este hueco, evidente en $\mathrm{T}$ e $\mathrm{Y}$, aparente en $\mathrm{F}$ y oculto en $\mathrm{E}$, muestra sin ningún género de dudas que estos cuatro testimonios -EFTY - del Libro de la caza de las aves se remontan a un antecedente común en el que existía ya esta laguna. Por tanto, podemos postular un estema parcial (situamos los elementos alfabéticamente):

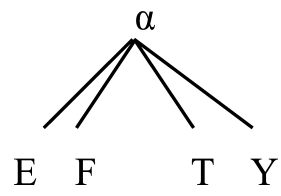

Pero podemos afinarlo un poco más todavía, puesto que es posible emparejar EY y hacerlos remontar hasta un antecedente común diferente de $\alpha$ y siempre posterior a [Siglo XV]. Ese antecedente común de EY es el que hemos señalado como $\beta$ y el motivo básico es que en ambos testimonios faltan los capítulos XVI, XXIII, XXVIII y XXXI-XLVII.

Es evidente que todo esto necesita de una investigación más profunda que explique con detalle y con otras variantes textuales las relaciones que acabamos de bosquejar.

Retomemos el comentario al estema de Cummins. La cuarta línea de descendencia, la que agrupa $\mathrm{C}$ y $\mathrm{H}$, es correcta en los dos argumentos utilizados: ambos testimonios se remontan a una copia realizada en Nápoles en 1446. Y no cabe duda de que $\mathrm{C}$ es descendiente directo de $\mathrm{H}$ (codex descriptus).

La quinta familia, $\mathrm{ONN}_{1}$, se introduce sin explicación alguna. Los únicos motivos que pueden esgrimirse son que los tres testimonios se conservan en la Biblioteca del Palacio Real de Madrid y que $\mathrm{N}$ y $\mathrm{N}_{1}$, además, se encuentran reunidos en un mismo códice (BPR, ms. II/1370). Cummins no ofrece dato alguno que justifique el antecedente común [?].

El último grupo familiar, conformado por DIK, supuestamente se remonta a una copia realizada en 1416 y que incorpora unas recetas independientes. Tal y como está formulado, esta agrupación es absolutamente errónea. Solo D declara expresamente que su antecedente es de 1416:

Aqui acaua el libro de la | caza de las aues; fue escripto y acabado | en la cibdad de bretaña en el mes de enero | Año del Señor de jUcccc.xvj. Años. E deste | dicho libro yo, Alonso Sanches de Cala | clerigo presbitero, cura de la Yglesia de Sant | bre. de car $^{\mathrm{a}}$ (fol. 94v) 
Los otros dos testimonios IK no presentan este colofón. Ciertamente, la ausencia del colofón no es un indicio muy fuerte porque estos pueden suprimirse al no creer el copista que se trata de un elemento constitutivo de la obra y es fácilmente sustituible por el suyo propio ${ }^{91}$. La prueba del poco valor que le concedían los amanuenses lo podemos ver en el tratamiento que le han dado al colofón original de Ayala, que publicó Lafuente Alcántara y reeditaron Gutiérrez de la Vega y Fradejas Lebrero pero que Montandon-Hummel consideraba un amaño moderno. Como ya hemos mostrado, solo lo conserva Bb.

Es cierto que DIK presentan unas recetas independientes comunes cuyo incipit lee «Las cosas que ha menester que no está doliente del buche» y el explicit «mojar toda la cola y darle as de comer el coplonsillo». Se trata de un breve recetario con siete capítulos de desigual extensión. A pesar de que DIK comparten este texto ${ }^{92}$ una serie de hechos imposibilita reunir estos tres testimonios en un mismo grupo.

El texto del Libro de la caza de las aves, según lo conocemos por todas las ediciones que se han publicado y la mayoría de los testimonios conservados comienza con unos preliminares: invocación, carta-dedicatoria, prólogo y tabla. Después distribuye el contenido del tratado propiamente dicho de la manera siguiente:

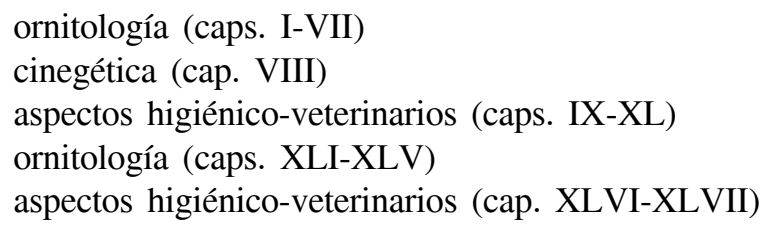

Sin embargo, D no presenta esta distribución, sino que agrupa todos los capítulos ornitológicos en un bloque inicial (caps. I-XI), al que se sigue el cinegético (cap. XII) y por último el higiénico-veterinario (caps. XIII-XLVI). Así, tras el capítulo en el que describe los alfaneques (cap. VII) vienen los dedicados a los azores (cap. VIII), los gavilanes (cap. IX), los esmerejones (cap. X) y el paso de las aves (cap. XI). Por otra parte, el capítulo del regimiento del neblí (cinegética) se encuentra dividido en 35 reglas, subdivisión que no presentan IK.

\footnotetext{
${ }^{91}$ Es el caso de I, que dice: «Aquí se acaba el libro de la caça de las aves, el qual conpuso e ordenó el bulen cavallero pero lópez de ayala, e muy nobles cossas e consejos en el gover|namiento e regimiento de las aves de caça. | Deo gracias» (fol. 67v). Además, este colofón no aparece al finalizar el texto de Ayala (fol. 66v) sino a continuación de una anécdota apócrifa redactada en primera persona: «Otrosi, si tu falcón no quisiere tomar el agua de día por quantas cosas le fi|zieres pruévagela de noche a la candela en vn baçín o en buena camella e soy | çierto que luego la tomará. Esto yo lo vi fazer a vn falcon baharí del Rey» (fol. 67v).

${ }^{92}$ Este mismo recetario se encuentra en $\mathrm{P}$ y V, extremo que se le escapó a Cummins en su edición.
} 
En conclusión, no cabe relacionar genealógicamente estos tres manuscritos, o por lo menos D no puede descender del mismo subarquetipo del que proceden IK.

Manuel Delgado Montoto. En la primavera de 1999 Manuel Delgado Montoto defendió su tesis doctoral, una edición crítica del Libro de la caza de las aves. Era un trabajo que necesitaba de una profunda revisión para que pudiera ser publicado. Él mismo reconocía que

he cometido un error que deberá haber [sic] corregido: he recopilado las variantes de cada familia pero en esta primera etapa no me había fijado todavía si esa variante era la lectura correcta o no y en la redacción presentada he opuesto a las variantes de cada familia el «texto crítico» cuando debería haber puesto «otros manuscritos» ${ }^{93}$.

El autor decidió que permaneciera inédita, como lo evidencia el hecho de que no aceptó la publicación en microfichas, como era costumbre en la UNED. Sin embargo, tras su muerte (10.11.2004) han aparecido tres ediciones que son una reproducción de aquel trabajo ${ }^{94}$.

A pesar de las carencias, la edición Delgado Montoto supone un gran avance en el conocimiento de la transmisión e historia textual del Libro de la caza de las aves por dos hechos básicos: 1) no se limita a las copias del siglo XV y 2) en el aparato crítico emplea todos los testimonios que se conocían en ese momento $^{95}$. El elenco de los manuscritos parte de la lista que ofrecía la edición

\footnotetext{
${ }^{93}$ Delgado Montoto, ed. cit., pág. 7.

${ }^{94}$ La primera edición se publicó, por entregas, en Analecta calasanctiana («Edición crítica del Libro de la caza de las aves de Pero López de Ayala», Analecta Calasanctiana, 93, 2005, págs. 11-112; 94, 2005, págs. 11-112; 95, 2006, págs. 11-118 y 96, 2006, págs. 11-160). Recogía el estudio y la edición dividida en cuatro partes. Finalizada la publicación en fascículos, ese mismo año se recopilaron en un volumen todo lo publicado en Analecta calasanctiana (Edición crítica del "Libro de la caza de las aves», de Pero López de Ayala, Madrid, Ediciones Calasancias, 2006). Al año siguiente, 2007, apareció una nueva edición, que se presenta como « $1^{\mathrm{a}}$ edición revisada» en la que se incorporaban partes de la tesis doctoral que no habían sido publicadas en las dos versiones anteriores (Edición crítica del «Libro de la caza de las aves», de Pero López de Ayala, Madrid, Ediciones Calasancias, 2007): el glosario (págs. 491-506), la bibliografía (507511), un apéndice de 30 hojas con la reproducción de una hoja de cada uno de los manuscritos utilizados en la edición y, como introito, las notas que Delgado Montoto utilizó en el acto de defensa (pág. 5-7). De estas adiciones se da cuenta en la solapa posterior de la cubierta: «Dejamos constancia de las correcciones que se han incorporado en esta edición sobre las publicaciones anteriores [...] Con ello puede lucir al completo este pormenorizado estudio». Esta última es la que usaremos a lo largo de nuestra argumentación, salvo que se indique lo contrario.

${ }^{95}$ Montandon-Hummel solo tomó «las variantes de los manuscritos N [= O], M [=H], P [=M] y R [=N], todos del siglo XV» (ed. cit., pág. 39) y Cummins se limitó a «las variantes que parecen constituir una posible lectura alternativa, o una forma léxica lo suficientemente distinta de la misma palabra como para merecer ser notada. Si una variante es claramente errónea, no aludimos a ella salvo en aquellos casos que pueden iluminar la cuestión del parentesco de los manuscritos, o que presentan algún interés léxico inherente» (ed. cit., pág. 37).
} 
de Fradejas Lebrero ${ }^{96}$, que amplió Fradejas Rueda ${ }^{97}$ y a los que Delgado Montoto añadió cuatro nuevos elementos ${ }^{98}$. De todos ellos presenta una sucinta ficha catalográfica ${ }^{99}$ y reproduce una hoja de cada testimonio al final del volumen.

La edición se basa en el ms. T ( $Y_{1}$ según su clasificación), aunque la argumentación por la que seleccionó este testimonio como base de su edición no es muy convincente. Explica que tras realizar «una serie de catas en todos los manuscritos del siglo XV, en lugares diferentes», lo que le ha «permitido excluir algunos» testimonios (aunque no indica cuáles ni por qué), se decidió por T «porque está muy bien conservado, su letra es clara y es de los manuscritos más completos con muy pocas lagunas» ${ }^{100}$. Desestimó A (B en su listado) «porque tiene muchos aragonesismos, algunas lagunas y es una versión bastante estudiada y trillada» ${ }^{101}$.

El resumen de su investigación se plasma en un estema ${ }^{102}$ muy interesante que justifica a lo largo de 34 páginas $^{103}$, pero en el que no pudo situar cuatro testimonios, $\mathrm{Bb}, \mathrm{Cc}, \mathrm{I}$ y $\mathrm{Q}$ :

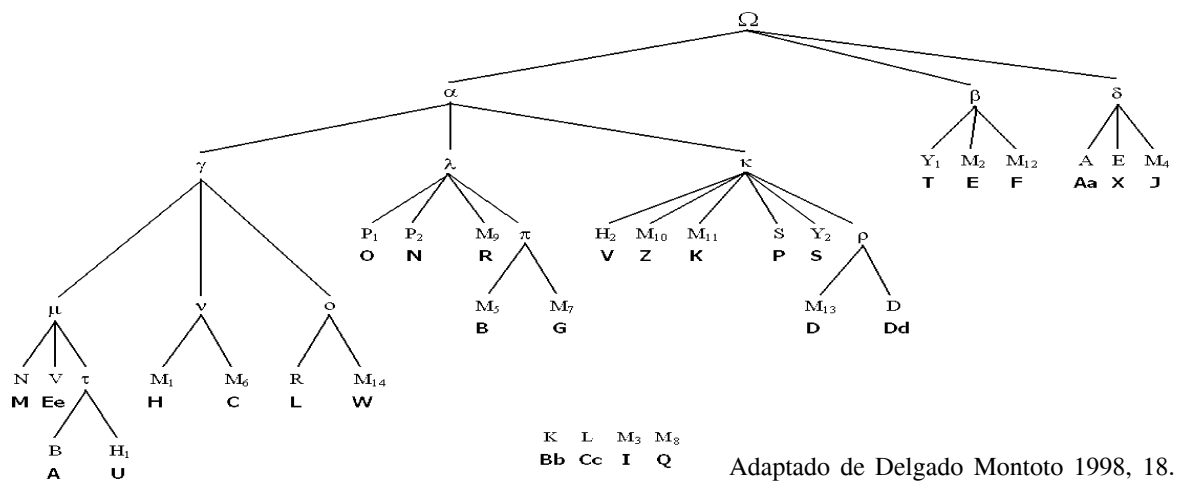

${ }^{96}$ Fradejas Lebrero, ed. cit., págs. 43-44.

${ }^{97}$ José Manuel Fradejas Rueda, «Los manuscritos del Libro de la caza de las aves: intento de un censo y descripción del ms. Krahe», Epos, 5, 1989, págs. 497-504 y en Bibliotheca cinegetica hispanica: bibliografía crítica de los libros de cetrería y montería hispano-portugueses anteriores a 1799, London, Grant \& Cutler, 1991, págs. 60-62.

${ }^{98}$ De los nuevos testimonios que aporta Delgado Montoto (ed. cit., págs. 6 y 12) —L [= Cc], $\mathrm{A}[=\mathrm{Aa}], \mathrm{D}[=\mathrm{Dd}]$ y V $[=\mathrm{Ee}]$ - da noticia José Manuel Fradejas Rueda en «Otro manuscrito más del Libro de la caça de las aves de Pero López de Ayala», Notas y estudios filológicos, 7, 1992, págs. 149-158; y en «Prolegómenos a una edición «común» del Libro de las caza de las aves de Pero López de Ayala», en Actas del III Congreso de la Asociación Hispánica de Literatura Medieval, Salamanca, Biblioteca Española del Siglo XV, 1994, pág. 336.

99 Delgado Montoto, ed. cit., págs. 13-18.

${ }^{100}$ Ibíd., pág. 20.

101 Ibídem.

102 En esta adaptación, las siglas más cercanas a las líneas de transmisión son las utilizadas por Delgado Montoto; las que hay inmediatamente debajo son las que empleamos en este trabajo. Para el listado completo véase el Apéndice y la explicación que se ofrece en la nota 2.

103 Ibíd., págs. 21-55. 
Por otra parte, se lamenta de que el estema no es «claro» porque «no se conserva ningún manuscrito desde que se escribió el original (1386) hasta bien entrado el siglo $\mathrm{XV}{ }^{104}$. Parte de una premisa errónea: no tuvo en cuenta el que varias copias posteriores se remontan a antígrafos de principios del siglo XV. Es decir, no acepta la máxima recentiores non deteriores. Varios testimonios declaran que son copia de otros anteriores. Dd y D informan que su original es de $1416^{105}$ :

\section{Dd}

Aquí acaba el libro dela caça | delas aues: fue escripto \& a|cabado en la cibdad de bretaña en $\mid$ el mes de enero. Año del Señor de jUcccc. | xvj. Años. E deste dicho libro yo | Alonso sanches de cala | clerigo presbitero | cura dela yglesia de sant $\mid b^{\mathrm{e}} \mathrm{r}$. de car $^{\mathrm{a}}$. (fol. 68r)

\section{$\mathrm{D}$}

Aquí acaua el libro de la | caza de las aues. Fue escripto y acabado | en la cibdad de Bretaña en el mes de enero | Año del Señor de jUccccxvj Años. E deste | dicho libro yo Alonso sanches de cala clérigo presbítero cura de la Yglesia de sant | bre. de car ${ }^{\mathrm{a}}$ (fol. 94v)

mientras que $\mathrm{C}$ y $\mathrm{H}$ indican que se remontan a un testimonio de 1446:

\section{$\mathrm{H}$}

El presente libro fue acabado dios sea lohado en | Napoles la biespra de todos santos por manos | de ximen lopez. | Anyo m. ccccxlvj ${ }^{\circ}$ (fol. 73v)

\section{C}

El presente libro fue acabado | dios loado en Napoles la | vispra de todos santos por $\mid$ manos de ximeno lo|pez. Año. de | M. cccc. | xlvj (fol. 100v)

Las familias que estableció son a todas luces posibles, aunque algunos de los argumentos que ofrece sean endebles o estemáticamente inútiles ${ }^{106}$. No siempre ha utilizado los mejores argumentos para justificar el establecimiento de una familia.

Por ejemplo, para la familia $\delta$ establece diez loci critici explicados con cierto detalle a los que añade una extensa lista de 223 casos, en donde localiza

104 Ibíd., pág. 21.

105 Z (BNE, 4261) presenta el mismo colofón: «Aqui acaba el libro de·la caza de·las aves | fue escripto e acabado en·la cibdad de Bre|taña en el mes de enero Año del señor | de 1416 años e de este dicho libro Yo | Alonso Sanchez de Cala Clerigo presbi|tero cura de-la Yglesia de S. Barth $^{\mathrm{e}}$. de Cartag ${ }^{\mathrm{a}} . »$ (fol. 88v). Pero no se puede tener en cuenta ya que es una adición de mano posterior para completar una copia mútila de la obra de Ayala.

106 Se trata de modernizaciones léxicas — peligro en vez de ocasión (pág. 51), dizen por llaman (pág. 54), un par de ellos por una copla de ellos (pág. 54) - e inversiones —así plumage por plumage así (pág. 26), por fuerça entrar en vez de entrar por fuerça (pág. 26), e oí e vi por e vi e oí (pág. 32), e çévanse en vez de e se çevan (pág. 33), andan todos por en vez de andan por todas (pág. 34)—. Estos y otros muchos casos, como copdiçiar por cobiçiar (pág. 55), son muy fáciles de explicar y carecen de validez estemática. 
muchas más «pruebas de la familia $\delta »{ }^{107}$. Pero no tuvo en cuenta una prueba fundamental, las amplificationes que AaXJ presentan en los capítulos XVIII:

\& oy dezjr a algunos caçadores buenos que quando el falcon tiene plumada vieja \& la non pueden lançar que es buena cosa darle al falcon o ave una quantia de rrauano qual entendier el caçador segun fuer el cuerpo del falcon lo qual le aprouechara \& que algunos lo prouaron muchas vezes \& los fazian lançar agua \& rraeduras viejas del buche (Aa, fol. 56v)

y XXI:

Et oy dezjr que algunas vezes acaesçe que se estremeçe el ave \& cae commo muerta en el suelo ansi subitamente \& esta es vna dolencia que llaman gorrion \& dezia pero menjno falconero que fue del rrey muy prouado en esta arte del qual se faze mençion para esta dolencia atal non auja otra tal cosa mejor que tomar tres moscas de perro \& ponlas por la boca de la aves que tal dolençia auja \& fazer gelas tragar \& que luego guareçeria. Et que en muchas partidas del mundo preguntara desta dubda a muchos caçadores que commo se guareçeria esta dolençia que dizen gorrion \& non fallaron otra mejor que esta que yo aqui digo (Aa, fol. $59 \mathrm{v})$

Esta es una prueba incontestable, no como la que recoge, por ejemplo, como locus criticus $3^{108}$. Aquí el texto crítico propuesto lee romeros y la familia $\delta$ romanos, que no es, además, una lectura exclusiva de $\delta$ puesto que también se documenta en NLW, es decir, en miembros de las familias $\lambda(\mathrm{N})$ y $\omega(\mathrm{LW})$. Es un error que fácilmente podrían cometer varios copistas independientemente.

Delgado Montoto podría haber afinado aún más la familia $\delta$. Considera que los tres testimonios Aa, J y X son descendientes directos de su antecedente inmediato $\delta$. Sin embargo, es fácilmente demostrable que $\mathrm{X}$ es un codex descriptus de Aa.

En un momento indeterminado, siempre antes de que se copiara $\mathrm{X}$, Aa perdió un folio, el folio 59. El fol. 58v finaliza con la rúbrica y las primeras palabras del capítulo XX:

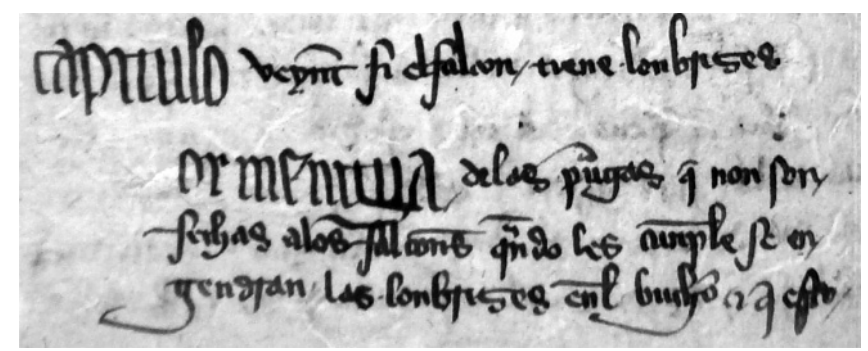

Aa: Madrid, Alba, ms. 94, fol. 58v

107 Delgado Montoto, ed. cit., págs. 31-37.

108 Ibíd., pág. 32. 
y en el folio siguiente (marcado en lapicero como 60), prosigue:

cnlos tpos ghe aupte orpos bueno romalal. delas abpas en bna oo $\beta$ laxpiar ponla $\beta$ bre e $L$

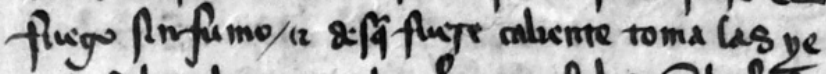

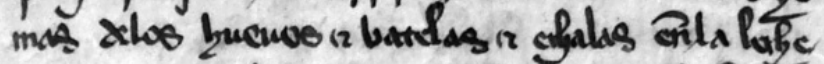

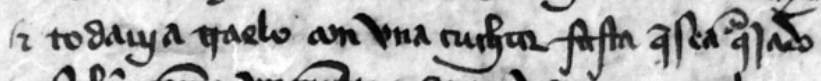

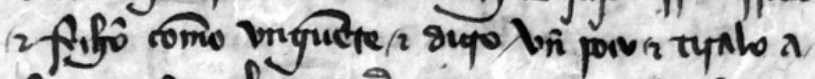

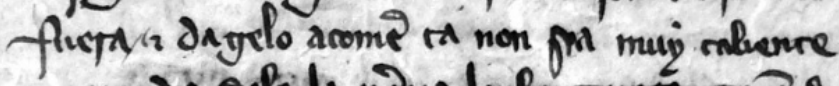

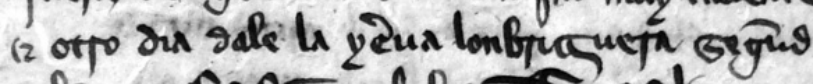

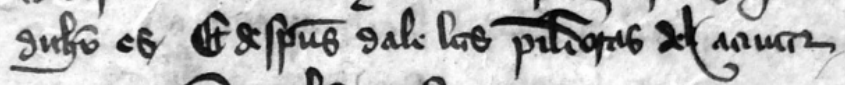

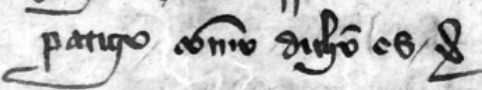

Aa: Madrid, Alba, ms. 94, fol. 59r

Este texto constituye la parte final de este capítulo $\mathrm{XX}^{109}$. Observemos ahora las primeras líneas de este capítulo en $\mathrm{X}$ (fol. 52v):

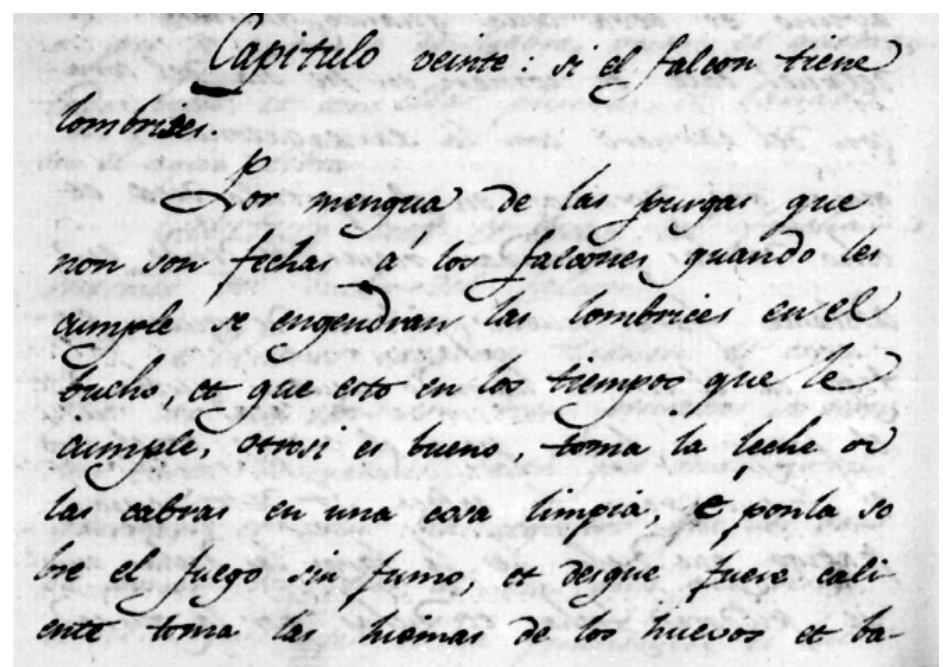

X: Madrid, RAE, ms. 26, fol. 52v

${ }^{109}$ Delgado Montoto afirma que «falta parte del capítulo XIX y XX» (ed. cit., pág. 18); en realidad el capítulo XIX está completo. 
La quinta y sexta líneas leen «...cumple se engendran las lombrices en el | bucho et que esto en los tiempos que el cumple...». Si se observan las palabras en cursiva se verá que et que esto son las tres últimas palabras del folio $58 \mathrm{v}$ de Aa y que en los tiempos corresponden a las tres primeras del hoy folio $59 \mathrm{r}$ de Aa (originalmente 60r). Delgado Montoto ${ }^{110}$ no menciona este hecho en su aparato crítico, donde solo reflejó que la lectura crítica «e que esto sea verdat» aparece como «el gesto sea verdat» en $\mathrm{P}$ y «y esto veese porque» en D y Dd.

Por otra parte, Delgado Montoto estableció que de $\Omega$ (que nosotros interpretamos como el antecedente común de todos los testimonios que este editor estudió, no como el original que salió de la pluma del Canciller en 1386) se hicieron tres copias $\alpha, \beta$ y $\delta$. Acabamos de ver que la familia $\delta$ está plenamente justificada. La familia $\beta$, constituida por los testimonios EFT y que hemos visto más arriba, también es correcta.

Ahora bien, a falta de un estudio más detallado y profundo, hay hechos que parecen indicar que $\beta$ y $\delta$ no son descendientes inmediatos o directos de $\Omega$, sino que entre ellos y $\Omega$ hubo una copia de la que surgen $\beta$ y $\delta$. Por el momento, el dato más interesante que apunta en esta dirección es una omisión común a EFTAaXJ, que se encuentra en el capítulo XXII y que no se puede explicar por homoioteleuton. El texto crítico del capítulo XXII lee:

toma la milsana e en el fin del libro fallarás que yerva es, e muélela e dale el polvo de ella en la carne, otros llaman miransolis que son cañamones montesinos e tienen los boticarios, e si non podieres aver la milsana toma la yerva que dizen capili veneris, otros la llaman culantro ${ }^{111}$.

Toda la oración en cursiva —otros llaman miransolis que son cañamones montesinos e tienen los boticarios - falta tanto en EFT como en AaJX:

EFT

toma la mjel sana \& en·el fin del libro la | fallaras que yerua es \& muele-la \& dale el poluo della $\mid$ en la carne \& sy non podieres auer la mjel sana toma | la yerua que dizen capili venjs otros la llaman culantro del pozo ( $\mathrm{T}$, fol. 124r)
AaJX

toma la miel sana \& en·el fin del libro fallaras que yerua es, \& muelela \& dale el pol|uo della en·la carne \& si non podieres aver la mjel | sana toma la yerua que llaman capilele benjs otros | la llaman culantro del poço (Aa, fol. 61r)

Esto permite postular que EFT y AaJX tienen un antecedente común. Por tanto, podríamos reformular el estema propuesto por Delgado Montoto de la siguiente manera:

\footnotetext{
110 Ibíd., pág. 287.

111 Ibíd., págs. 301-302.
} 


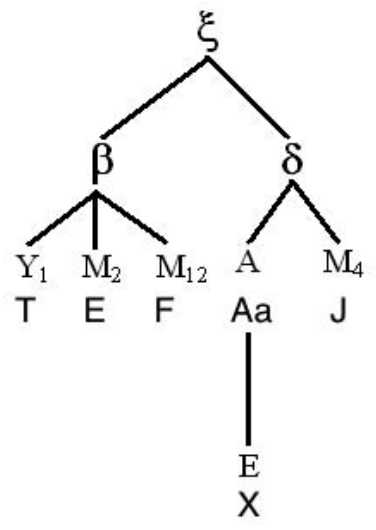

$\mathrm{Al}$ final de las justificaciones en las que explica las variantes que le han llevado a organizar las distintas familias y subfamilias, Delgado Montoto presenta una subfamilia que designa con la sigla $\varepsilon^{112}$, pero se trata de una familia fantasma porque no da relación de los manuscritos que la constituyen ni en el estema ${ }^{113} \mathrm{ni}$ en un cuadro anterior ${ }^{114}$. Los datos utilizados para establecerla son ${ }^{115}$ :

$\begin{array}{llll}\text { Cap. } & \text { Línea } & \varepsilon & \text { Texto crítico } \\ \text { II } & 92 & \text { Espelúzdranse } & \text { Espelúzanse } \\ \text { VI } & 26 & \text { Lengua de oca } & \text { Lenguadoc } \\ \text { VIII } & 604 & \text { Ven ren...e } & \text { Ve rendido e } \\ \text { XXXIV } & 13 & \text { Copdiçiar } & \text { Cobdiçiar } \\ \text { XXXIV } & 23 & \text { Puedan ser y dados } & \text { Puedan y ser dados } \\ \text { XXXV } & 45 & \text { Aztor } & \text { Açor } \\ \text { XXXIX } & 18 & \text { El bargo } & \text { El enbargo } \\ \text { XLII } & 2 & \text { De caça muy lindos } & \text { De caça e muy lindos } \\ \text { XLII } & 70 & \text { Buena e buen rostro } & \text { Buena carne e biuen (sic) rostro } \\ \text { XLIII } & 4 & \text { E ha en ellos } & \text { E ha en los }\end{array}$

Analicemos estos datos a la vista del aparato crítico. La mayor parte de las variantes aducidas no permiten establecer un grupo textual ${ }^{116}$. Y las tres varian-

112 Ibíd., pág. 55.

113 Ibíd., pág. 23.

114 Ibíd., pág. 22.

${ }^{115}$ Ibíd., pág. 55.

116 Copdiçiar (XXXIV.13) y aztor (XXXV.45) son meras variantes de lengua sin valor estemático alguno. Simples inversiones que varios copistas han podido cometer individualmente son puedan ser y dados (XXXIV.23) y de caça muy lindos (XLII.2), aunque la lección crítica editada lee de caça muy lindas e gentiles (ed. cit., pág. 433). La variante que presenta como característica de la familia $\varepsilon$ en XXXIX.18 (ed. cit., 413) se documenta en los testimonios MEeH, que pertenecen a las familias $\mu$ (MEe) y $v(\mathrm{H})$. Es una lección de poco, por no decir nulo, valor 
tes que pudieran justificar la existencia de la familia $\varepsilon$ - espelúzdranse, Lengua de oca y Buena e buen rostro- no están recogidas en ningún testimonio.

Tal y como la presenta y argumenta, la familia $\alpha$ es válida. Pero sería necesario afinarla un poco. A la vista de los datos que ofrecen los manuscritos, cabe la posibilidad de que $\mathrm{C}$ sea un codex descriptus de $\mathrm{H}$ y está claro que W lo es de L. Al final del manuscrito L, un tal Pedro Pérez cuenta:

Yo Pedro perez caçador Tube en Aragon. A tres de Julio | año de 1561. Vn halcon catalan bahary de peña | gregera limpio y mudado de la primera muda. | y por ser cosa tan admirable. Se Asento en este libro por | memoria. Año. dia. ut supra (ms. L, fol. 71r)

y en W, copia del siglo XIX, leemos:

Yo Pedro Perez caçador tuve en Ara|gon á tres de Julio del año de 1561 un | halcon catalan bahary de Peña Gragera | limpio y mudado de la primera muda. | Y por ser cosa tan admirable se asento en | este libro por memoria. Año. dia ut sulpra (ms. W, fol. 136r)

Si tenemos en cuenta los datos y sugerencias que hemos presentado en las páginas anteriores, podremos reformular el estema que propuso Delgado Montoto $^{117}$ del siguiente modo:

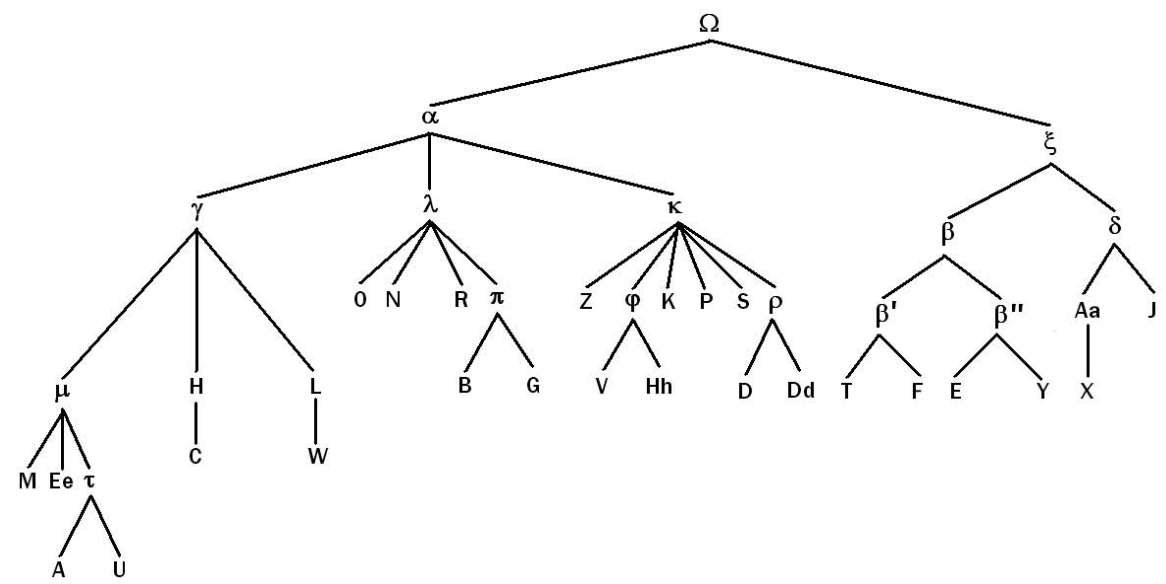

estemático al tratarse de una haplografía silábica. La variante localizada en VIII.604 no la documenta Delgado en ningún testimonio; las variantes que ofrece el aparato crítico son: «que vee rendido] garça que tiene rendida $M_{1}$; que tiene rendida $M_{6}$; que vee tendido $M_{7}$; que viere rendido $M_{10}, M_{13}$, $\mathrm{D}$; que vieren rendido $\mathrm{M}_{14}$ [=HCGZDDdW] (ed. cit., pág. 209). La lección de $\varepsilon$ aducida en XLIII.4 tampoco se documenta en ninguno de los testimonios recogidos. El texto crítico editado lee $E$ ha en los esmerejones (ed. cit., pág. 441), y las variantes que ofrece son « $\mathrm{E}$ ha ellos $\mathrm{B}, \mathrm{N}, \mathrm{M}_{1}, \mathrm{M}_{14}, \mathrm{~V}$ [=AMHWEe]; que ha en ellos $\mathrm{Y}_{2}[=\mathrm{S}] »$. En cualquier caso, su valor filiativo es despreciable.

117 Ibíd., pág. 23, en la edición original de 1998 se encuentra en la pág. 18. 
Toda nueva edición crítica de un texto dado parte, por lo general, de la insatisfacción con las versiones existentes, tanto de los testimonios que lo transmiten como de los intentos editoriales que se han llevado a cabo. Creemos haber mostrado, en las páginas anteriores, que ninguna de las ediciones que se han publicado en los últimos 150 años (desde 1869 hasta 2007) cumple los criterios filológicos aunque permiten tener una visión de la obra y de las dificultades que puede entrañar su edición.

Por otra parte, desde la última edición — la de Delgado Montoto defendida en 1998 - se han localizado cuatro nuevos testimonios: Y, Ff, Gg y Hh. Dos de ellos se ubican fácilmente dentro de la tradición manuscrita: Y, como se ha mostrado, se sitúa claramente en la familia $\xi$, y dentro de ella en la subfamilia $\beta$ ', y Hh en la familia $\alpha^{118}$; no así $\mathrm{Ff}^{119}$ y $\mathrm{Gg}^{120}$. Nuestro objetivo será, por tanto, revisar detenidamente el estema propuesto por Delgado Montoto, modificar los elementos que pueden ser reubicados, situar los nuevos testimonios y preparar una nueva edición crítica.

Para esta nueva edición crítica primero realizaremos la transcripción codificada según el sistema TEI de todos y cada uno de los testimonios. Esto nos permitirá tener una potente base de datos de informaciones textuales que nos facilitará la compulsa de cualquier lectura en cualquier momento a la vez que ayudará a la construcción de un aparato crítico completo y no selectivo. Las ediciones digitales de los testimonios se ofrecerán a través del servidor del Ar-

${ }^{118}$ A falta de un análisis detenido, creemos que Hh comparte antecedente común inmediato ( $\varphi$ ) con $\mathrm{V}$, por lo que, en principio, formaría parte de la familia $\kappa$.

${ }^{119}$ Ff, localizado en enero de 2008 en la Biblioteca Nazionale di Napoli (mss. I-E-60), descrito por Fradejas Rueda («De nuevo sobre...», cit., págs. 1106-1108) y analizado por Laura Ramello en «Il Libro de la caza de las aves di Pero López de Ayala e i suoi epigoni: tradizioni manoscritta e problemi», en Per le vie del mondo, Torino, Università degli Studio di Torino/Trauben, 2009, págs. 73-86, se encontraba recogido en el catálogo decimonónico de Alfonso Miola, Notizie di manoscritti neolatini. Parte prima. Mss. francesi, provenzali, spagnuoli, catalani e portoghesi della Biblioteca Nazionale di Napoli, Napoli, Presso Federigo Furchheim, 1895, págs. 80-81. Datable en el siglo XV, presenta al final un texto de los que se ha venido etiquetando como $R e$ cetas varias (fols. 60r-62r), que coincide con el que presentan los testimonios DDdHhIKPQVZ y cuyo incipit dice «Las cosas que ha menester quando está doliente del buche». Por otra parte, se relaciona con el ms. Q (BNE, 10321) puesto que ambos presentan dos capítulos que no aparecen en ninguna otra copia de la obra: uno dedicado al «falcón que tiene el papo roto» (cap. XVII) y acerca del «falcón que tiene güérfago» (cap. XXXIII).

$120 \mathrm{Gg}$, localizado en enero de 2010 en manos de un coleccionista privado, es un curioso ejemplar datable en la década de 1580-1590 en el que se hallan reunidos el Libro de la caza de las aves de Pero López de Ayala (fols. 2r-61r) y los dos primeros libros del Libro de acetrería y montería de Juan Vallés (fols. 64r-170v). La copia de Ayala presenta un colofón en el que declara cuál es su antígrafo: «Aqui se acaba el libro de la caça de las aues e fue escrito e acabado [fol. 61r] por juan bueno fijo de Martin Sanchez de Mendia a 23 | de agosto año del Nascimiento de Nuestro Señor Don Jesuchristo, de 1427 | en·la·uilla de Veluas (?) en casa de Pero Yanez de Novia» (Gg, fols. 60v-61r). Un nuevo antecedente del siglo XV hasta ahora desconocido. 
chivo Iberoamericano de Cetrería (www.aic.uva.es). La tarea más ardua será la selección de un texto de base, es decir, de un término de comparación para determinar las variantes y, también, de un manuscrito de base que permita presentar una versión lingüísticamente próxima al idiolecto de Pero López de Ayala. Deberíamos, para esto último, seleccionar un manuscrito copiado en el siglo XV, lo más limpio posible de los rasgos orientales, especialmente los aragonesismos que tanto abundan en un amplio número de testimonios, y a la vez lo más próximo al antecedente común inmediato de todos los testimonios, es decir, que posea el número mínimo posible de testimonios reconstruidos (arquetipos).

\section{APÉNDICE}

A continuación presentamos la relación de todos los testimonios que conocemos del Libro de la caza de las aves. La primera sigla es la que utilizamos nosotros y que se remonta a las establecidas por Cummins en su edición ${ }^{121}$, seguidas por Orduna ${ }^{122}$ y regularizadas por Fradejas Rueda ${ }^{123}$. Las que se encierran entre paréntesis corresponden a las empleadas por Delgado Montoto en su tesis doctoral y posteriores publicaciones de la misma y que se remontan a las establecidas por Fradejas Rueda ${ }^{124}$. En el caso de los testimonios Ff, Gg, Hh e Y no hay sigla entre paréntesis porque se trata de cuatro nuevos elementos de la tradición manuscrita del Libro de la caza de las aves.

A (=B), Londres, British Library, Add. 16392, XV, c. 1430

Aa (=A), Madrid, Casa de Alba, ms. 94, XV,

B $\left(=\mathrm{M}_{5}\right)$, Madrid, BNE, ms. 1464, XVI, a. 1562

$\mathrm{Bb}(=\mathrm{K})$, Madrid, Javier Krahe, XV

C $\left(=\mathrm{M}_{6}\right)$, Madrid, BNE, ms. 2022, XVI, h. 1580

Cc (=L), Monforte de Lemos, Colexio, XV

D $\left(=M_{13}\right)$, Madrid, BNE, ms. 2914, XVIII

Dd (=D), París, Musée de la Chasse, ms. 63-100.2, XVI

E $\left(=M_{2}\right)$, Madrid, BNE, ms. 2970, XV-XVI, h. 1510

Ee $(=\mathrm{V})$, Vaticano, BAV, Ottob. Lat. 3324, XV

$\mathrm{F}\left(=\mathrm{M}_{12}\right)$, Madrid, BNE, ms. 3350, XVII

Ff (-) Nápoles, BNE, ms. I. E. 60, XVI

$\mathrm{G}\left(=\mathrm{M}_{7}\right)$, Madrid, BNE, ms. 4208, XVI, h. 1580

Gg (-), Madrid, Privado, XVI, d. 1556

$\mathrm{H}\left(=\mathrm{M}_{1}\right)$, Madrid, BNE, ms. 4260, 1446

\footnotetext{
121 Cummins, ed. cit., págs. 23-32.

122 Orduna, art. cit., págs. 895-899.

123 Fradejas Rueda, «De nuevo sobre...», cit.

${ }^{124}$ Fradejas Rueda, «Los manuscritos...», cit.; «Otro manuscrito más...», cit. y «Prolegómenos...», cit., págs. 335-342.
} 
Hh (-), Madrid, Bonomi, 1535

I $\left(=\mathrm{M}_{3}\right)$, Madrid, BNE, ms. 7195, XV-XVI, d. 1507

J $\left(=\mathrm{M}_{4}\right)$, Madrid, BNE, ms. 9684, XV-XVI, h. 1530

$\mathrm{K}\left(=\mathrm{M}_{11}\right)$, Madrid, BNE, ms. 10180, XVI-XVII

L (=R), Madrid, RAH, ms. 9-28-3/5495, XV-XVI, h. 1520

M (=N), París, BNF, ms. esp. 292, XV, h. 1450

N (= $\left.\mathrm{P}_{2}\right)$, Madrid, Real Biblioteca, Ms. II/1370, XV, h. 1450

$\mathrm{N}_{1}\left(=\mathrm{P}_{2}\right)$, Madrid, Real Biblioteca, Ms. II/1370, XV

$\mathrm{O}\left(=\mathrm{P}_{1}\right)$, Madrid, Real Biblioteca, ms. II/1366, XV, h. 1445

$\mathrm{P}(=\mathrm{S})$, Salamanca, Universidad, ms. 2305, XVII

Q $\left(=\mathrm{M}_{8}\right)$, Madrid, BNE, ms. 10321, XVI, h. 1580

R $\left(=\mathrm{M}_{9}\right)$, Madrid, BNE, ms. 10322, XVI, h. 1590

$\mathrm{S}\left(=\mathrm{Y}_{2}\right)$, New Haven, Beinecke, ms. 79, XVI

$\mathrm{T}\left(=\mathrm{Y}_{1}\right)$, New Haven, Beinecke, ms. 138, XV

$\mathrm{U}\left(=\mathrm{H}_{1}\right)$, Nueva York, HSA, ms. B2583, XV, 1472?

V $\left(=\mathrm{H}_{2}\right)$, Nueva York, HSA, B-2584, XVI, 1543

W $\left(=\mathrm{M}_{14}\right)$, Madrid, BNE, ms. 5959, , XIX

X (=E), Madrid, RAE, ms. 26, XVIII

Y (-), Mercogliano, Montevergine, ms. 17, XVI

$\mathrm{Z}\left(=\mathrm{M}_{10}\right)$, Madrid, BNE, ms. 4261, XVI-XVII

\section{BIBLIOGRAFÍA}

Badía Andreu, Joaquín, reseña de José Gutiérrez de la Vega, Libro de la caza de las aves, et de sus plumages, et dolencias, et melecinamientos. Del canciller Pedro López de Ayala, en Libros de cetrería de el príncipe y el canciller, Madrid, M. Tello, 1879, en La Ilustración Venatoria, 8, 1885, págs. 6768.

Ciceri, Marcella, reseña de Pero López de Ayala, Libro de la caza de las aves. El MS 16.392 (British Library, Londres), ed. de John G. Cummins, London, Tamesis Books, 1986, en RF, 100, 1988, págs. 469-471.

Conde, Juan Carlos, reseña de Madelaine Montandon-Hummel, Libro de cetrería: edición basada en los códices del siglo XV, tesis de doctorado, Basilea, la autora, Discount Print, 1986, en Dicenda: Cuadernos de Filología Hispánica, 10, 1991-1992, págs. 349-354.

Corfis, Ivy A., reseña de Pero López de Ayala, Libro de la caza de las aves. El MS 16.392 (British Library, Londres), ed. de John G. Cummins, London, Tamesis Books, 1986, en HR, 58, 1990, págs. 110-112.

Delgado Montoto, Manuel, «Edición crítica del Libro de la caza de las aves de Pero López de Ayala», Analecta Calasanctiana, 93, 2005, págs. 111-112; 94, 2005, págs. 111-112; 95, 2006, págs. 111-118; 96, 2006, págs. 111-160.

Delgado Montoto, Manuel, Edición crítica del «Libro de la caza de las aves», de Pero López de Ayala, Madrid, Ediciones Calasancias, 2006.

Delgado Montoto, Manuel, Edición crítica del «Libro de la caza de las aves», de Pero López de Ayala, Madrid, Ediciones Calasancias, 2007.

Delgado Montoto, Manuel, Edición crítica del Libro de la caza de las aves, de Pero López de Ayala, Madrid, UNED, tesis de doctorado, 1998.

Fradejas Rueda, José Manuel, Antiguos tratados de cetrería castellanos, Madrid, Caïrel, 1985.

Fradejas Lebrero, José Manuel, reseña de Pero López de Ayala, Libro de la caza de las aves. El MS 16.392 (British Library, Londres), ed. de John G. Cummins, London, Tamesis Books, 1986, en Ínsula, 493, diciembre 1987, págs. 5-6. 
Fradejas Rueda, José Manuel, reseña de Pero López de Ayala, Libro de la caza de las aves. El MS 16.392 (British Library, Londres), ed. de John G. Cummins, London, Tamesis Books, 1986, en Epos, 4, 1988, págs. 481-486.

Fradejas Rueda, José Manuel, «Los manuscritos del Libro de la caza de las aves: intento de un censo y descripción del ms. Krahe», Epos, 5, 1989, págs. 497-504.

Fradejas Rueda, José Manuel, Bibliotheca cinegetica hispanica: bibliografía crítica de los libros de cetrería y montería hispano-portugueses anteriores a 1799, London, Grant \& Cutler, 1991.

Fradejas Rueda, José Manuel, «Otro manuscrito más del Libro de la caça de las aves de Pero López de Ayala», Notas y estudios filológicos, 7, 1992, págs. 149-158.

Fradejas Rueda, José Manuel, Evangelista's «Libro de cetrería»: A fifteenth-century satire of falconry books, London, King's College London Centre for Late Antique and Medieval Studies, 1992.

Fradejas Rueda, José Manuel, «Prolegómenos a una edición «común» del Libro de las caza de las aves de Pero López de Ayala», en Actas del III Congreso de la Asociación Hispánica de Literatura Medieval (Salamanca, 3 al 6 de octubre de 1989), Salamanca, Biblioteca Española del Siglo XV, 1994, págs. 335-342.

Fradejas Rueda, José Manuel, El Arte de cetrería de Federico II, Madrid, Testimonio - Ciudad del Vaticano, Biblioteca Apostólica Vaticana, 2004.

Fradejas Rueda, José Manuel, «De nuevo sobre los manuscritos del Libro de la caça de las aves de Pero López de Ayala», en Homenaje a César Hernández Alonso, Valladolid, Universidad y Diputación Provincial, 2008, págs. 1.099-1.115.

Garcia, Michel, reseña de Pero López de Ayala, Libro de la caza de las aves. El MS 16.392 (British Library, Londres), ed. de John G. Cummins, London, Tamesis Books, 1986 en Bulletin of Hispanic Studies, 77, 1990, pág. 183.

Gier, Albert, reseña de Madelaine Montandon-Hummel, Libro de cetrería: edición basada en los códices del siglo XV, tesis de doctorado, Basilea, la autora, Discount Print, 1986, en Revue de Linguistique Romane, 51, 1987, págs. 596-397.

Gier, Albert, reseña de Pero López de Ayala, Libro de la caza de las aves. El MS 16.392 (British Library, Londres), ed. de John G. Cummins, London, Tamesis Books, 1986 en Zeitschrift für romanische Philologie, 104, 1988, págs. 394-396.

Gómez Redondo, Fernando, reseña de Pero López de Ayala, Libro de la caza de las aves. El MS 16.392 (British Library, Londres), ed. de John G. Cummins, London, Tamesis Books, 1986, en Vox Romanica, 47, 1988, págs. 298-302.

Gutiérrez de la Vega, José, «Libro de la caza de las aves, et de sus plumages, et dolencias, et melecinamientos. Del canciller Pedro López de Ayala», en Libros de cetrería de el príncipe y el canciller, Madrid, M. Tello, 1879, págs. 136-344.

Hook, David, reseña de Pero López de Ayala, Libro de la caza de las aves. El MS 16.392 (British Library, Londres), ed. de John G. Cummins, London, Tamesis Books, 1986, en Journal of Hispanic Philology, 14, 1989-1990, págs. 178-181.

Lafuente Alcántara, Emilio y Gayangos, Pascual de, El Libro de las aves de caça del canciller López de Ayala con las glosas del Duque de Alburquerque, Madrid, Bibliófilos Españoles, 1869.

Leguina, Enrique de, reseña de José Gutiérrez de la Vega, Libro de la caza de las aves, et de sus plumages, et dolencias, et melecinamientos. Del canciller Pedro López de Ayala, en Libros de cetrería de el príncipe y el canciller, Madrid, M. Tello, 1879, en La Ilustración Venatoria, 8, 1885, pág. 43.

López de Ayala, Pero, Libro de la caza de las aves, J. Fradejas Lebrero, ed., Madrid, Castalia (Odres Nuevos), 1959.

López de Ayala, Pero, Libro de la caza de las aves, J. Fradejas Lebrero, ed., Madrid, Castalia (Odres Nuevos), 1969. 
López de Ayala, Pero, Libro de la caza de las aves. El MS 16.392 (British Library, Londres), ed. J. G. Cummins, London, Tamesis Books, 1986.

Miola, Alfonso, Notizie di manoscritti neolatini. Parte prima. Mss. francesi, provenzali, spagnuoli, catalani e portoghesi della Biblioteca Nazionale di Napoli, Nápoles, Presso Federigo Furchheim, 1895.

Montandon-Hummel, Madelaine, «Libro de cetrería: edición basada en los códices del siglo XV», tesis de doctorado, Basilea, la autora, Discount Print, 1986.

Nelson, Jan Alan, «A Critical Edition of the Livro de citraria», tesis de doctorado, University of North Carolina, 1964.

Orduna, Germán, «Libro de la caça de las aves», en C. Alvar y J. M. Lucía Megías, coords., Diccionario filológico de literatura medieval española: Textos y transmisión, Madrid, Castalia, 2002, págs. 895-899.

Paz y Melia, Antonio, «Libro de cetrería de Evangelista y una profecía del mismo, con prólogo, variantes, notas y glosario», Zeitschrift für romanische Philologie, 1, 1877, págs. 222-246.

Ramello, Laura, «Il Libro de la caza de las aves di Pero López de Ayala e i suoi epigini: tradiziones manoscritta e problemi», en Per le vie del mondo, Turín, Università degli Studio di Torino - Trauben, 2009, págs. 73-86.

Revilla, Manuel, reseña de José Gutiérrez de la Vega, Libro de la caza de las aves, et de sus plumages, et dolencias, et melecinamientos. Del canciller Pedro López de Ayala, en Libros de cetrería de el príncipe y el canciller, Madrid, M. Tello, 1879, en La Ilustración Venatoria, 8, 1885, pág. 27.

Van den Abeele, Baudouin, reseña de Pero López de Ayala, Libro de la caza de las aves. El MS 16.392 (British Library, Londres), ed. de John G. Cummins, London, Tamesis Books, 1986, en Scriptorium, 44, 1, 1990 = Bulletin Codicologique, 1, n 195, pág. *60.

Fecha de recepción: 1 de junio de 2010

Fecha de aceptación: 9 de junio de 2010 